\title{
A recurring YYDRXG pattern in broadly neutralizing antibodies to a conserved site on SARS-CoV-2, variants of concern, and related viruses
}

Hejun Liu'1,7, Chengzi I. Kaku²,7, Ge Song³, Meng Yuan¹, Raiees Andrabi³, Dennis R. Burton ${ }^{3,4}$, Laura M. Walker ${ }^{2,5, *}$, Ian A. Wilson ${ }^{1,6, *}$

${ }^{1}$ Department of Integrative Structural and Computational Biology, The Scripps Research Institute, La Jolla, CA 92037, USA

${ }^{2}$ Adimab, LLC, Lebanon, NH 03766, USA.

${ }^{3}$ Department of Immunology and Microbiology, The Scripps Research Institute, La Jolla, CA 92037, USA

${ }^{4}$ Ragon Institute of MGH, MIT and Harvard, Cambridge, MA 02139, USA

${ }^{5}$ Adagio Therapeutics, Inc., Waltham, MA 02451, USA

${ }^{6}$ The Skaggs Institute for Chemical Biology, The Scripps Research Institute, La Jolla, CA, 92037, USA

7 These authors contributed equally

* Corresponding authors: wilson@scripps.edu (I.A.W.), laura.walker@adimab.com (L.M.W.) 


\section{ABSTRACT}

Studying the antibody response to SARS-CoV-2 informs on how the human immune system can respond to antigenic variants as well as other SARS-related viruses. Here, we structurally and functionally characterized a potent human antibody ADI-62113 that also neutralizes SARS-CoV2 variants of concern and cross-reacts with many other sarbecoviruses. A YYDRxG motif encoded by IGHD3-22 in CDR H3 facilitates targeting to a highly conserved epitope on the SARS-CoV-2 receptor binding domain. A computational search for a YYDRxG pattern in publicly available sequences identified many antibodies with broad neutralization activity against SARS-CoV-2 variants and SARS-CoV. Thus, the YYDRxG motif represents a common convergent solution for the human humoral immune system to counteract sarbecoviruses. These findings also suggest an epitope targeting strategy to identify potent and broadly neutralizing antibodies that can aid in the design of pan-sarbecovirus vaccines and antibody therapeutics.

Short Summary: Decryption of a recurrent sequence feature in anti-SARS-CoV-2 antibodies identifies how potent pan-sarbecovirus antibodies target a conserved epitope on the receptor binding domain. 


\section{INTRODUCTION}

2 The current pandemic of coronavirus disease 2019 (COVID-19) has fomented devasting

3 sociological and global economic consequences. Although several effective vaccines have been

4 rapidly developed, SARS-CoV-2, the etiological cause of COVID-19, is still raging throughout the world. The efficacy of these vaccines has been affected by viral antigenic drift that has led to enhanced infectivity as well as escape neutralizing antibodies elicited by SARS-CoV-2 infection and vaccination. A majority of the potent neutralizing antibodies target the receptor binding domain (RBD) of the spike protein. However, these antibodies are often susceptible to mutations at the receptor binding site (RBS), which are frequently found in circulating SARS-CoV-2 variants

10 (R. E. Chen et al., 2021; Hoffmann et al., 2021; P. Wang, M. S. Nair, et al., 2021; Yuan, Huang, 11 et al., 2021; Yuan, Liu, et al., 2021). Notwithstanding, a subset of broadly neutralizing antibodies

12 (bnAbs) can target more conserved surfaces on the spike protein of the virus and can neutralize

13 circulating variants of concern (VOC), variants of interest (VOI), and often other SARS-related

14 viruses in the sarbecovirus family (Jette et al., 2021; Li et al., 2021; Liu et al., 2020; H. Liu et al.,

15 2021; Pinto et al., 2020; Rappazzo et al., 2021; Starr, Czudnochowski, et al., 2021; Tortorici et

16 al., 2021; Wec et al., 2020). Identification and characterization of such cross-neutralizing

17 antibodies are therefore urgently needed to fight the current COVID-19 pandemic, as well as

18 prepare for future potential zoonotic spillover.

Despite their broad spectrum of neutralization activity against SARS-CoV-2, circulating

20 and emerging variants, as well as other related coronaviruses with high pandemic risk, potent

21 cross-neutralizing antibodies are rarely isolated compared to SARS-CoV-2-specific neutralizing

22 antibodies. To date, only a limited number of cross-neutralizing antibodies that target regions in

23 spikes that are highly conserved across sarbecoviruses, which include the CR3022 site and the

24 N343 proteoglycan site in the RBD, as well as the S2 domain (Jette et al., 2021; Jiang et al., 2021; 
25 Li et al., 2021; Liu et al., 2020; H. Liu et al., 2021; Martinez et al., 2021; Piccoli et al., 2020; Pinto

26 et al., 2020; Rappazzo et al., 2021; Sakharkar et al., 2021; Sauer et al., 2021; Starr,

27 Czudnochowski, et al., 2021; Tortorici et al., 2021; Wec et al., 2020; Yuan, Liu, et al., 2021; Zhou

28 et al., 2020; Zhou et al., 2021). We and others have reported structures of cross-neutralizing

29 antibodies targeting the CR3022 site with potent neutralization against SARS-CoV-2, circulating

30 and emerging variants, and other sarbecoviruses (Jette et al., 2021; Liu et al., 2020; Tortorici et

31 al., 2021). However, the frequency that these cross-neutralizing antibodies are elicited by SARS-

32 CoV-2 infection and vaccination, and why they are so rarely isolated, remain to be determined.

33 Here, we structurally characterized such a cross-neutralizing antibody ADI-62113. We identified

34 a recurrent YYDRxG motif in ADI-62113 encoded by IGHD3-22 in heavy-chain complementarity-

35 determining region $3(\mathrm{CDR} H 3)$ from comparative analysis of the crystal structure of another

36 cross-neutralizing antibody COVA1-16. A computational search of publicly available sequences

37 with a YYDRxG sequence pattern identified more such antibodies that broadly neutralize SARS-

38 CoV-2 VOC and SARS-CoV pseudoviruses, suggesting a general mechanism harnessed by the

39 human humoral immune system to combat sarbecoviruses. Such information is critical for next-

40 generation vaccine design and evaluation, as well as discovery of more effective therapeutic

41 antibodies with increased breadth. Our study further suggests such cross-neutralizing bnAbs can

42 be rapidly identified from their sequence alone.

\section{RESULTS}

44 Antibody ADI-62113 cross-reacts with a broad spectrum of sarbecoviruses

45 ADI-62113 is a potent cross-neutralizing antibody isolated from a COVID-19 patient (Sakharkar

46 et al., 2021). Immunoglobulin heavy variable gene IGHV1-3 and kappa variable gene IGKV1-33

47 encode its heavy and light chain, respectively, and these germline genes have not been reported

48 in other SARS-CoV-2 cross-neutralizing antibodies to date. To assess antibody breadth, we 
expressed various sarbecovirus RBDs on the surface of yeast to characterize their binding

50 kinetics with antibody ADI-62113. ADI-62113 binds with high affinity to a broad spectrum of

51 sarbecoviruses including ACE2-utilizing viruses in clade 1 and non-ACE2-utilizing viruses in clade

522 (Figure 1A). Thus, its binding properties are highly favorable as a potential pan-sarbecovirus

53 prophylactic or therapeutic.

\section{ADI-62113 binds a highly conserved site on SARS-CoV-2 RBD}

55 To understand the basis of the broad reactivity of ADI-62113, we determined the crystal structure 56 of ADI-62113 in complex with SARS-CoV-2 RBD at $2.6 \AA$ resolution (Figure S1 and Table S1).

57 ADI-62113 binds to the highly conserved CR3022 binding site (Yuan et al., 2020), but with an 58 approach angle that can still block ACE2 receptor binding (Figure 1B), which in part explains its 59 high neutralization potency against SARS-CoV-2. Of note, the approach angle and binding mode 60 is very similar to another cross-neutralizing antibody, COVA1-16, that we reported previously, 61 although the heavy chain variable domain of COVA1-16 is encoded by a different gene IGHV16246 (Liu et al., 2020) (Figure S1A).

63 Further analysis of the antibody binding interface revealed that ADI-62113 CDR H3 64 dominates the interaction with SARS-CoV-2 RBD, contributing nearly $70 \%$ of the total buried 65 surface area (BSA) on the RBD, as calculated by the PISA program (Krissinel \& Henrick, 2007) 66 (Figure 1C). The CDR H3 forms a $\beta$-strand like interaction with a SARS-CoV-2 RBD core $\beta$-strand 67 through three main-chain to main-chain hydrogen bonds (Figure S1B). The aromatic ring of $V_{H}$ 68 Y99 interacts with aliphatic moiety of RBD K378 (Figure 1D). $V_{H}$ Y100 forms a $\pi-\pi$ interaction with 69 the RBD peptide backbone of ${ }_{382} \mathrm{VS}_{383}$. $\mathrm{V}_{\mathrm{H}} \mathrm{R} 94$ interacts with the main-chain carbonyl of RBD 70 G413, and $V_{H} R 97$ with RBD D427 and F429 carbonyl oxygens. $V_{H}$ Q101 forms equivalent 71 hydrogen bond pairs with RBD Q414. The somatically mutated $V_{H} R 100 b$ has multiple interactions 72 with the RBD where its aliphatic moiety interacts with the aromatic ring of F377, and its 
73 guanidinium group forms three hydrogen bonds with the backbone of RBD ${ }_{369} \mathrm{YNS}_{371}$ and the

74 partially negative dipole at the C-terminus of a short a-helix in the RBD, as also observed in

75 COVA1-16 (Liu et al., 2020). The indented, negatively charged surface on the RBD in this region

76 is highly suited for engagement with $V_{H} R 100 b$ (Figure S2A). Of note, in the native spike trimer,

77 this region is located in the interface between two adjacent RBDs, where this negative patch is

78 engaged by R408 of a neighboring RBD in the "down" state, which may explain why arginine is

79 naturally favored in ADI-62113 and COVA1-16 for interacting with this RBD site (Figure S2B). All

80 of these epitope residues in the RBD are highly conserved across sarbecovirus sequences

81 analyzed (Figure 1C and Figure S3), which supports the broad spectrum cross-reactivity observed

82 for ADI-62113 against sarbecoviruses (Figure 1A).

\section{A YYDRxG motif shared between antibodies ADI-62113 and COVA1-16}

84 Of note, we observed that CDR H3 of ADI-62113 exhibits near-identical interactions with the RBD

85 relative to COVA1-16 despite differences in IGHV gene usage (Figure S1A-B). Interactions with

86 other subsites seem have less impact on the binding mode as different interactions of RBD R408

87 with ADI-62113 and COVA1-16 light chains did not change the antibody approach angle or the

88 binding mode of CDR H3. From comparison of these two structures, we identified that the

89 centerpiece of the antibody paratopes, $\mathrm{V}_{\mathrm{H}}{ }_{99} \mathrm{YYDR}_{\mathrm{X}} \mathrm{G}_{100 \mathrm{~d}}$ hexapeptide, forms a conserved local

90 structure for interaction with highly conserved residues in the RBD (Figure 2A).

91 A $\beta$-bulge is formed near the tip of CDR $\mathrm{H} 3$ (Figure 2B-C) after a type $1 \beta$-turn $\left(\mathrm{V}_{\mathrm{H}}\right.$

$92{ }_{100 a} \mathrm{DRRG}_{100 \mathrm{~d}}$ in this case) at its apex. An extra residue is inserted in the down strand of the $\beta$ -

93 hairpin at residue $V_{H} Y 100$ e and creates a G1 $\beta$-bulge, where the glycine residue in the bulge is

94 in a left-handed a-helical conformation (Chan et al., 1993; Craveur et al., 2013; Richardson et al.,

95 1978). The carbonyl oxygen of $V_{H}$ D100a forms a typical hydrogen bond in type I $\beta$-turns to the

96 amide of $V_{H}$ G100d. The negatively charged side-chain carboxyl of $V_{H} D 100 a$ is then able to 
97 hydrogen bond to the backbone amides of $V_{H} R 100 c$ in the $\beta$-turn and $V_{H} Y 100 e$ in the $\beta$-bulge, 98 which may further stabilize the local structure of the $\beta$-bulge.

101 et al., 1978) (n.b. normally first position in traditional G1 numbering but labeled as i+3 here to

102 avoid confusion with $\beta$-turn numbering of the preceding turn). In this case, $V_{H} G 100 d$ has a 103 positive phi $(\phi)$ angle $\left(\phi=88^{\circ}, \psi=11^{\circ}\right)$, consistent with the glycine residue in a $\mathrm{G} 1 \beta$-bulge that

104 alters the backbone conformation (Figure 2C) and enables a hydrogen bond to be made between

105 its carbonyl oxygen and the hydroxyl of the highly conserved RBD S383 (Figure 2D). The 106 presence of the additional residue in the G1 $\beta$-bulge motif alters the subsequent register of the $\beta$ 107 sheet comprising the $\beta$-hairpin, thereby allowing for accommodation of an additional residue 108 (Chan et al., 1993). The $\mathrm{V}_{\mathrm{H}} \mathrm{Y} 100 \mathrm{e}$ side chain subsequently flips from a down configuration in the $109 \beta$-sheet to an up configuration (Figure $2 \mathrm{C}$ ), thus opening up space for $\mathrm{V}_{\mathrm{H}} \mathrm{Y} 100$ to interact with the 110 RBD (Figure 2D). The insertion of an extra residue into the $\beta$-sheet accentuates the typical right111 handed twist of the $\beta$-sheet (Craveur et al., 2013), which may contribute to the structural stability

112 and specificity of CDR H3 in its interaction with the RBD (Figure S1A). Moreover, the spatial 113 constraint observed between the tip of CDR $\mathrm{H3}$ of $\mathrm{ADI}-62113$ and ${ }_{382} \mathrm{VSPTL}_{386}$ region in RBD may 114 additionally drive the preference for a glycine in the $\beta$-bulge in ADI-62113 and COVA1-16 (Figure $1152 \mathrm{D}$ and Figure S2C). Overall, this structural comparison of two cross-neutralizing antibodies, ADI11662113 and COVA1-16, enabled identification of a unique pattern that includes the YYDRxG 117 peptide where a register shift occurs in the $\beta$-hairpin through an insertion of a $\beta$-bulge. These 118 features help promote twisting of $\beta$-sheet of the $\beta$-hairpin, contributing to potential stabilization of 119 this particular conformation of the extended CDR H3. Importantly, the YYDRxG motif combines 120 strong polar, hydrophobic, and $\pi-\pi$ interactions with the CR3022 site on the RBD (Figure 2A), 
121 providing a structural basis for the potent and broad neutralization against SARS-CoV-2, VOCs,

122 and other related viruses.

123 Most YYDRxG motifs are encoded by IGHD3-22 gene

124 Given these shared features were derived entirely from two cross-neutralizing antibodies (ADI-

12562113 and COVA1-16), we sought to perform a computational pattern search to evaluate whether

126 similar features might be present in any other antibodies with sequences deposited in public

127 databases (Figure 3A). Of note, the CDR3 must be of sufficient length (here $\geq 18$ residues by

128 IMGT definition) to enable the YYDRxG hexapeptide to reach the conserved binding site on RBDs

129 as observed for ADI-62113 and COVA1-16 (Figure S2D). Hence, length constraints in both N-

130 terminal ( $\geq 5$ aa) and C-terminal ( $\geq 7$ aa) of the YYDRxG hexad were a requirement during the

131 YYDRxG pattern search. Sequence homology to the YYDRxG hexapeptide was also used in the

132 search since $V_{H} Y 99, V_{H} Y 100$, and $V_{H} R 100 b$ all form hydrophobic interactions with the RBD,

133 which may be possible with other residues containing hydrophobic moieties. In a search of over

134 205,000 antibody sequences, 153 antibodies with an YYDRxG pattern in their CDR H3 were

135 identified (Tables S2-3). All sequence hits have the YYDRxG motif or close homologues in their

136 CDR H3 (Figure S4A). Immunoglobulin gene analysis shows that the IGHD3-22 gene is highly

137 enriched. The D regions in CDR H3 in 88\% of the YYDRxG antibodies are encoded by the IGHD3-

13822 (Figure 3B), which is the same diversity gene used in ADI-62113 and COVA1-16 (Figure S1A),

139 compared to $8.5 \%$ antibodies in the overall search library (Figure S4B).

140 Of these 153 antibodies, 100 (65\%) were isolated from different cohorts consisting of

141 COVID-19 patients and mRNA vaccinees (Brouwer et al., 2020; E. C. Chen et al., 2021; Cho et

142 al., 2021; Gaebler et al., 2021; Graham et al., 2021; Kreer et al., 2020; Robbiani et al., 2020;

143 Sakharkar et al., 2021; Tong et al., 2021; Z. Wang, J. C. C. Lorenzi, et al., 2021; Z. Wang, F.

144 Muecksch, et al., 2021; Z. Wang, F. Schmidt, et al., 2021). All of the D regions in these anti- 
145 SARS-CoV-2 antibodies are exclusively encoded by IGHD3-22 (Figure 3C and Tables S3-4). In

146 contrast, there does not appear to be a strict constraint on IGHV and IGHJ gene usage (Figure

147 3D-E), consistent with the different IGHV gene usage of ADI-62113 and COVA1-16. Diverse sets

148 of IGHV and IGHJ genes are paired with IGHD3-22 in these antibodies, which is distinct from, but

149 overlap with, the YYDRxG antibodies identified in non-COVID cohorts (unrelated sources) (Figure

150 S4C-D). Some IGHV genes are more often paired with IGHD3-22 in these antibodies such as

151 IGHV3-30, IGHV4-39, IGHV3-33, and IGHV1-69, although the current number of antibodies

152 available for analysis ( $n=100$ for anti-SARS-CoV-2 antibodies vs. $n=53$ for other antibodies) may

153 limit conclusive determination of whether IGHV gene pairing preferences exist for this particular

154 subset of SARS-CoV-2 antibodies.

155 Somatic hypermutations, specific reading frame, and $\mathrm{N}$ addition to IGHD3-22 are required

156 Antibody coding sequence is a product of immunoglobulin gene recombination, namely $V(D) J$

157 recombination, non-templated addition ( $\mathrm{N}$ addition), and somatic hypermutation during $\mathrm{B}$ cell

158 development. The $\mathrm{V}(\mathrm{D}) \mathrm{J}$ junctional sequence encodes CDR H3 of an antibody. Three reading

159 frames (RFs) are possible for the IGHD3-22 due to random $\mathrm{N}$ additions, but the second RF is

160 exclusively observed in these YYDRxG antibodies since the other two result in either early

161 termination of translation (RF1) or a very different sequence (RF3) (Figure 4A). The situation

162 differs from the IGHD3-9 gene that is commonly used in broadly neutralizing anti-influenza stem

163 antibodies, where two of the three RFs are used to encode bnAbs (Wu et al., 2018). Moreover,

164 alignment of $\mathrm{CDR} \mathrm{H} 3$ coding sequences of representative neutralizing antibodies against SARS-

165 CoV-2 shows a high incidence of $T \rightarrow A / G$ or $A \rightarrow C$ transversions converting serine in the germline

166 sequence to arginine (Figure 4B), supporting the hypothesis that somatic mutation from the

167 germline serine to arginine residue in the YYDRxG motif ( $\mathrm{V}_{\mathrm{H}} \mathrm{R} 100 \mathrm{~b}$ in ADI-62113 or COVA1-16)

168 is critical for high affinity binding and neutralization (Liu et al., 2020). We also observe frequent 
somatic mutations adjacent to the serine codon (Figure 4A-B), which may be a lesion site created

170 during antibody affinity maturation and serve as a prerequisite of converting S100b to R100b in

171 germinal center as somatic hypermutation of A:T pairs requiring additional mutagenic process at

172 neighboring sites (Di Noia \& Neuberger, 2007; Franklin \& Blanden, 2006). In addition to the S100b

173 to R100b mutation in ADI-62113, mutation in a neighboring codon leads to somatically mutated

174 R100c (Figure 2B and Figure 4B). While $V_{H} R 100 b$ is critical for binding the $R B D, V_{H} R 100 c$ has

175 no interaction with RBD indicated by the paucity of side-chain electron density (Figure S2C). Thus,

$176 V_{H} R 100 c$ is not absolutely required since a serine at the same position does not impact binding,

177 as observed in COVA1-16 (Figure S1B). N additions (N1 and N2) at both ends of IGHD3-22 during

$178 \mathrm{~V}(\mathrm{D}) \mathrm{J}$ recombination seems important in determining the length of CDR H3 and the RF of IGHD3-

17922 that is critical in the positioning of YYDRxG in the CDR H3 $\beta$-hairpin. Overall, the requirement

180 for a specific RF, site-specific somatic hypermutation, and relatively long $\mathrm{N}$ additions at both ends

181 of IGHD3-22 may contribute to the low frequency of YYDRxG motif or its homologues in the

182 human antibody repertoire, which may in part explain the relatively rare occurrence of isolation of

183 such cross-neutralizing antibodies in COVID-19 patients and vaccinees.

184 YYDRxG motif associates with potent and broad anti-SARS-CoV-2 antibodies

185 Among antibodies identified with a YYDRxG motif, 28 (18\%) have been experimentally 186 characterized via SARS-CoV-2 neutralization assays (Figure 3A). 25 out of 28 (89\%) antibodies

187 recognize SARS-CoV-2 RBD and $22(79 \%)$ could effectively neutralize the virus as reported in 188 previous publications (Figure 5A and Table S2) (Brouwer et al., 2020; Cho et al., 2021; Graham

189 et al., 2021; Jette et al., 2021; Kreer et al., 2020; Sakharkar et al., 2021; Z. Wang, F. Muecksch,

190 et al., 2021; Z. Wang, F. Schmidt, et al., 2021), although data for cross-reactivity to VOCs and

191 other sarbecoviruses are incomplete. To determine whether the YYDRxG motif is associated with

192 broad antigen recognition, we tested available ADI antibodies (Sakharkar et al., 2021) against a 
193 panel of sarbecovirus RBDs. We observe that all antibodies, except ADI-63219 and ADI-62969,

194 strongly cross-react with multiple sarbecoviruses with apparent disassociation constants $K_{\mathrm{D}} \mathrm{App}^{\mathrm{Ap}}$

195 ranging from 1.0 to $30.6 \mathrm{nM}$ (Figure 5B and Figure S5). Despite the presence of the YYDRxG

196 hexapeptide, ADI-62969 and ADI-63219 show weak affinity to all sarbecovirus RBDs tested

197 including SARS-CoV-2. However, ADI-62969 and ADI-63219 have shorter or longer CDR H3 (19

198 or 25 residues by IMGT definition) compared to the others (average of 22 with a total range of 19-

19926 residues) that may restrict the positioning of YYDRxG for binding to the RBD (Table S2-3). We

200 further tested whether these antibodies cross-neutralize SARS-CoV-2 VOCs and SARS-CoV.

201 Using pseudotyped viruses, these YYDRxG antibodies showed effective neutralization against

202 Alpha, Beta, Gamma, and Delta VOCs, except again for ADI-63219 and ADI-62969 (Figure 5C

203 and Figure S6). Consistent with the sarbecovirus binding data, five out of six cross-reactive

204 antibodies neutralize SARS-CoV, albeit with variable potency ranging from 0.07 to $>10 \mu \mathrm{g} / \mathrm{ml}$.

205 Combining with cross-neutralization data for four other antibodies (Graham et al., 2021; Jette et

206 al., 2021; Liu et al., 2020; P. Wang, R. G. Casner, et al., 2021), nine (41\%) of these 22 neutralizing

207 antibodies could cross-neutralize SARS-CoV, albeit testing on another 11 (50\%) of these

208 antibodies against SARS-CoV may identify more such cross-neutralizing antibodies (Figure 5A).

209 In addition, we analyzed antibodies from available neutralization data to see whether there

210 was any preference in heavy chain or light chain variable gene segment usage paired with IGHD3-

21122 that was correlated with broad and/or cross-neutralization. We found several heavy and light

212 chain $\mathrm{V}$ genes in neutralizing antibodies with no obvious preference in gene usage, although

213 combinations of heavy and light variable genes in neutralizing antibodies are distinct from those

214 in non-neutralizing antibodies (Figure 5D). IGHV3-30, IGHV3-33, and IGKV3-20 were found to

215 encode the heavy chain variable domain in both neutralizing and non-neutralizing antibodies.

216 However, the small number of bnAbs that have been experimentally verified to date $(n=22$

217 neutralizing vs $\mathrm{n}=6$ non-neutralizing antibodies) preclude statistically meaningful analysis. 
218 Additional study of more YYDRxG antibodies will likely reveal how heavy and light chain genes

219 and CDR H3 length might impact neutralization potency. Overall, our data suggest YYDRxG

220 antibodies are broadly neutralizing antibodies for counteracting SARS-CoV-2 VOCs. Meanwhile,

221 they are strongly associated with cross-species neutralization as eight of 10 tested antibodies

222 exhibit cross-neutralization activity (Figure 5A and Table S2).

\section{YYDRxG pattern search identifies potent and broad antibodies against SARS-CoV-2 VOCs}

224 Of the YYDRxG antibodies against SARS-CoV-2, more than two thirds have only sequence

225 information available and have not been extensively evaluated or characterized (Figure 3A and

226 Table S3). The strong correlation between the YYDRxG motif with experimentally characterized

227 neutralizing antibodies suggested that these antibodies may broadly neutralize SARS-CoV-2

228 variants and potentially other sarbecoviruses, as observed in the antibodies that have been tested

229 in the neutralization assay (Figure 5A and Table S2). Indeed, two representative antibodies with

230 only sequence information available, i.e. MOD8_P2_IgG_B11-P1369 and PZF12_P2_IgG_F7-

231 P1369, were selected from the computational search and showed broad neutralization against

232 SARS-CoV-2, Alpha, Beta, Gamma, Delta, and SARS-CoV, although PZF12_P2_IgG_F7-P1369

233 has a lower potency against SARS-CoV. all the VOCs and SARS-CoV (Figure 6A). Further

234 analysis of 80 YYDRxG antibodies isolated from 32 donors (Cho et al., 2021; Robbiani et al.,

235 2020; Z. Wang, J. C. C. Lorenzi, et al., 2021; Z. Wang, F. Muecksch, et al., 2021; Z. Wang, F.

236 Schmidt, et al., 2021) suggests that this type of antibody can be elicited in both infected and

237 vaccinated patients, as well as in COVID-19 patients who received mRNA vaccines post-recovery

238 (Figure 6B and Table S4). Collectively, these data strongly suggest the YYDRxG motif features

239 in anti-SARS-CoV-2 antibodies that have potent and broad neutralization activity. The discovery

240 of this YYDRxG pattern in antibodies against sarbecoviruses further support the notion that broad

241 antibodies can be more frequently elicited in the human immune system than initially thought, 
242 which is consistent with recent publications where some vaccinee and patient sera exhibit

243 detectable, although often diminished, neutralizing activity against SARS-CoV-2 VOCs and VOIs

244 (Greaney et al., 2021; He et al., 2021; Jalkanen et al., 2021; J. Liu et al., 2021; Pegu et al., 2021;

245 Z. Wang, F. Schmidt, et al., 2021; Wu et al., 2021; Yuan, Huang, et al., 2021).

\section{Discussion}

247 Overall, we report here on structural characterization of a cross-neutralizing antibody, ADI-62113,

248 that revealed a highly similar binding mode to the SARS-CoV-2 RBD that was first observed in

249 COVA1-16 (Liu et al., 2020). We found that antibody binding to a very highly conserved site on

250 the RBD appears to be determined primarily by the YYDRxG hexapeptide encoded by IGHD3-22

251 in CDR H3. The extensive interaction with the conserved CR3022 site on the RBD and

252 stabilization of the CDR H3 local structure by a $\beta$-bulge make the YYDRxG pattern a desirable

253 feature for specific RBD recognition (Figure 2 and Figure S2A), which appears to be even more

254 extensive than for the recurrent YYD sequences in HIV V2-apex targeting bnAbs (Andrabi et al.,

255 2015; Gorman et al., 2016). Using the YYDRxG pattern search, we were able to identify and verify

256 many more such antibodies as potent neutralizers of SARS-CoV-2, VOCs, and SARS-CoV.

257 Many RBS-targeting antibodies are highly potent for neutralizing specific SARS-CoV-2

258 viruses, but lack breadth of activity against emerging and circulating viruses (Andreano et al.,

259 2021; R. E. Chen et al., 2021; Hoffmann et al., 2021; Starr, Greaney, et al., 2021; Tortorici et al.,

260 2020; P. Wang, M. S. Nair, et al., 2021; Weisblum et al., 2020; Yuan, Huang, et al., 2021). The

261 CR3022 site is highly conserved and therefore an important site for broad and cross-neutralizing

262 antibodies (Liu et al., 2020; Yuan et al., 2020). Several potent antibodies, i.e. ADI-62113, COVA1-

263 16, C022, and S2X259, have now been structurally characterized that target the CR3022 site

264 (Jette et al., 2021; Liu et al., 2020; Tortorici et al., 2021). Even although their epitopes do not 
overlap with ACE2, they compete with binding by the human ACE2 receptor, which may in part explain their relatively high potency in neutralizing both SARS-CoV-2 and VOCs.

High throughput methodologies especially single cell technologies and deep sequencing

Kreye et al., 2020; Robbiani et al., 2020; Rogers et al., 2020; Zost et al., 2020). Recently, repertoire sequencing has provided massive databases of antibody sequences (Briney et al.,

271 2019; Soto et al., 2019). However, experimental characterization such as cloning, expression,

272 kinetics measurement, epitope binning, and structure characterization are more time-consuming 273 and sometimes resource limiting for studying the antibody response to SARS-CoV-2 infection and 274 vaccination. From a search of public human antibody sequences, we identified 100 anti-SARS-

275 CoV-2 antibodies containing a conserved YYDRxG motif exclusively encoded by IGHD3-22 gene 276 (Figure 3C and Table S2-3). The strong preference for one of the three possible reading frames 277 of IGHD3-22, the apparent requirement for somatic hypermutation at a specific position in this 278 region, local structural constraints, and the requirement for an extended length of CDR $\mathrm{H} 3$, make 279 these antibodies less abundant compared to some other neutralizing antibodies targeting SARS280 CoV-2 RBD. Our data and analysis show that antibodies with a YYDRxG pattern in their CDR H3 281 are more likely to target the highly conserved surface in sarbecovirus RBDs and to neutralize 282 SARS-CoV-2 VOCs, emerging variants, and SARS-CoV, indicating a common convergent 283 solution used by the human humoral immune system to counteract sarbecoviruses.

284 Finally, the high correlation between the presence of a YYDRxG pattern and broad 285 neutralization activity support its use as a sequence signature of broadly and cross-neutralizing 286 antibodies targeting this highly conserved site on the SARS-CoV-2 RBD as well as other related 287 coronaviruses. Since antibodies containing a YYDRxG feature can be elicited by both natural 288 infection and vaccination, interrogation of these signature sequences in serum can also serve as 289 biomarkers to evaluate vaccine breadth and guide rational design of next-generation vaccines. 


\section{Acknowledgements}

291 We thank Henry Tien for technical support with the crystallization robot, Jeanne Matteson and

292 Yuanzi Hua for contribution to mammalian cell culture, Wenli Yu for insect cell culture, Seiya

293 Kitamura for useful discussions, and Robyn Stanfield for assistance in data collection. We are

294 grateful to the staff of Stanford Synchrotron Radiation Lightsource (SSRL) Beamline 12-1 for

295 assistance. This work was supported by Adagio Therapeutics and by the Bill and Melinda Gates

296 Foundation INV-004923 (I.A.W., D.R.B.). This research used resources of the SSRL, SLAC

297 National Accelerator Laboratory, which is supported by the U.S. Department of Energy, Office of

298 Science, Office of Basic Energy Sciences under Contract No. DE-AC02-76SF00515. The SSRL

299 Structural Molecular Biology Program is supported by the DOE Office of Biological and

300 Environmental Research, and by the National Institutes of Health, National Institute of General

301 Medical Sciences (including P41GM103393). Extraordinary facility operations were supported in

302 part by the DOE Office of Science through the National Virtual Biotechnology Laboratory, a 303 consortium of DOE national laboratories focused on the response to COVID-19, with funding 304 provided by the Coronavirus CARES Act.

\section{Author Contributions}

306 H.L., C.I.K, L.M.W., and I.A.W. conceived and designed the study. H.L. and C.I.K. expressed and

307 purified the proteins for crystallization and the binding and neutralization assays. H.L. crystallized

308 the antibody-antigen complexes and determined the crystal structures. M.Y. helped with X-ray

309 diffraction data collection. H.L. and I.A.W. analyzed the structural data. H.L performed the

310 antibody data mining and sequence analysis. C.I.K. and L.M.W. provided binding antibody

311 breadth data. G.S., R.A., and D.R.B. provided neutralization data. H.L. and I.A.W wrote the paper

312 and all authors reviewed and/or edited the paper. 
bioRxiv preprint doi: https://doi.org/10.1101/2021.12.15.472864; this version posted December 17, 2021. The copyright holder for this preprint

(which was not certified by peer review) is the author/funder, who has granted bioRxiv a license to display the preprint in perpetuity. It is made available under aCC-BY-NC-ND 4.0 International license.

\section{Competing Interest Statement}

314 C.I.K. and L.M.W. are employees of Adimab, LLC and hold shares in Adimab, LLC. L.M.W. is an

315 employee of Adagio Therapeutics Inc. and holds shares in Adagio Therapeutics Inc. L.M.W. is an

316 inventor on a patent describing the ADI anti-SARS-CoV-2 antibodies. 

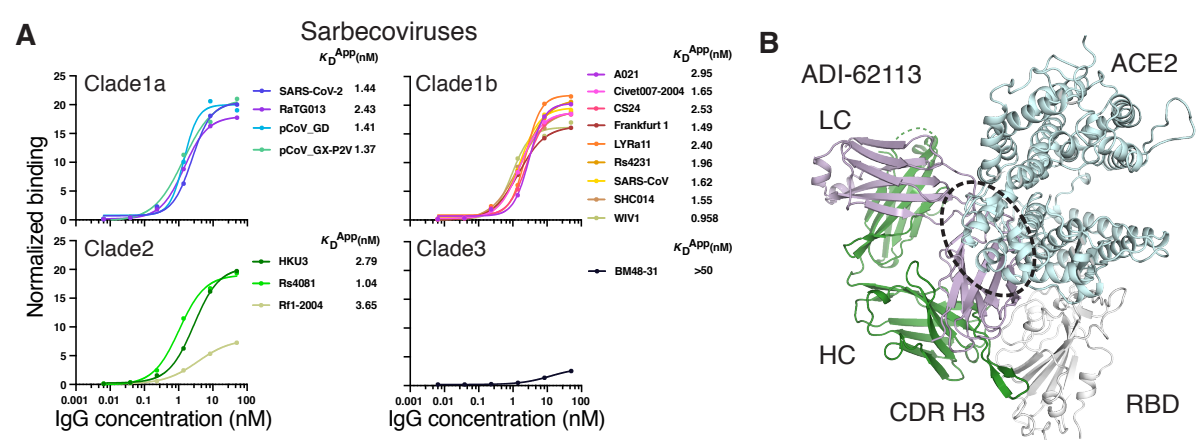

C
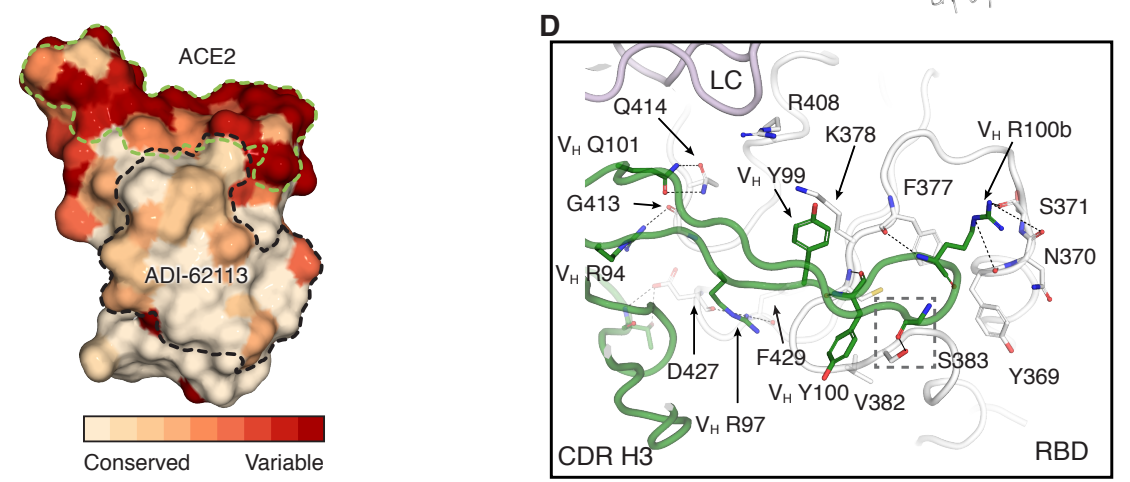

319 Figure 1. ADI-62113 binds a highly conserved site on SARS-CoV-2 RBD and cross-reacts

320 with many sarbecoviruses. A. ADI-62113 shows a broad spectrum of cross-reactivity to

321 sarbecoviruses. RBDs from viruses in clade 1a (SARS-CoV-2-like viruses), clade1b (SARS-CoV-

322 like viruses), clade 2, and clade 3 were displayed on the surface of yeast for binding kinetics

323 analysis. Clade $1 \mathrm{a}$ and $1 \mathrm{~b}$ viruses use ACE2 as an entry receptor. Clade 2 and 3 viruses do not

324 bind ACE2 but contain homologous sequences to SARS-CoV-2. B. Composite structure showing

325 ADI-62113 competition with ACE2 binding for SARS-CoV-2 RBD. ADI-62113 Fab, ACE2, and

326 SARS-CoV-2 RBD are shown in a ribbon representation. ACE2 is superimposed based on PDB

327 ID: 6M0J. White, RBD; pale cyan, ACE2; dark green, heavy chain; lavender, light chain. ADI-

32862113 binds to a highly conserved site on SARS-CoV-2 RBD, while the receptor binding site (RBS)

329 is highly variable across sarbecoviruses. C. ADI-62113 binds a highly conserved surface. SARS- 
330 CoV-2 RBD is shown in surface representation and colored by conservation across sarbecovirus

331 sequences. Dashed lines show the outline of the buried surface area (BSA) on the RBD by the

332 human receptor ACE2 (green) and ADI-62113 (black). 81\% of the ADI-62113 epitope surface is

333 buried by the heavy chain and $19 \%$ by the light chain. CDR H3 contributes $69 \%$ of the total BSA.

334 D. CDR H3 interacts with highly conserved residues in the RBD. The crystal structure of ADI-

33562113 in complex with SARS-CoV-2 RBD is shown in tube representation. Residues involved in

336 the interface between ADI-62113 and SARS-CoV-2 RBD are shown in sticks. Dashed lines

337 represent hydrogen bonds or salt bridges. $V_{H}$ R94, R97, R100b, G100d, and N101 hydrogen bond

338 with the RBD. $V_{H}$ Y99, Y100, and R100b have hydrophobic and $\pi-\pi$ interactions with the RBD.

339 The dashed box indicates potential space constraints for the glycine in the YYDRxG motif in CDR

$340 \quad \mathrm{H} 3$ as shown in Figure 2D. 


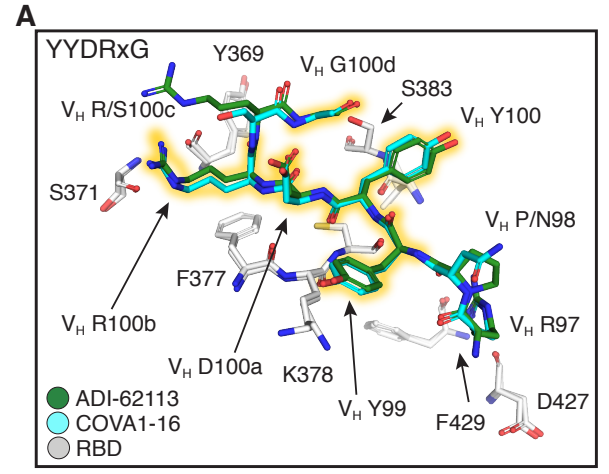

C

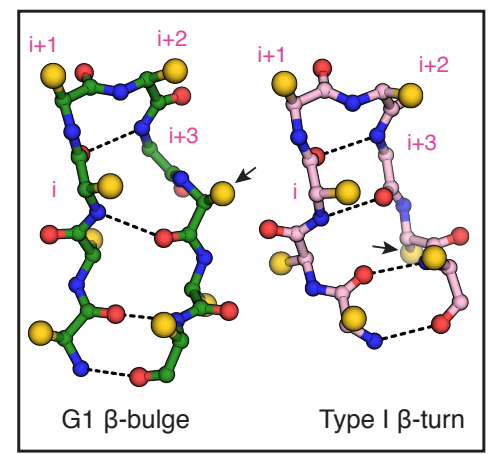

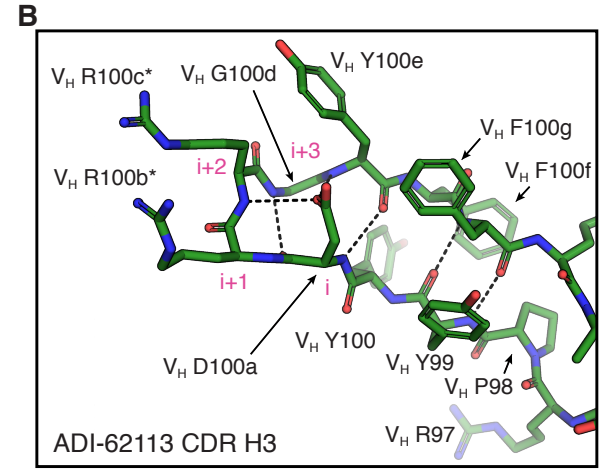

D

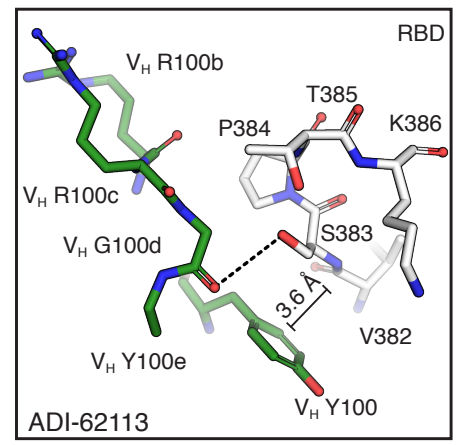

Figure 2. The YYDRxG motif is a recurring feature in CDR H3 for binding the RBD. Hydrogen

343 bonds are shown as dashed lines. Key residues are shown in sticks. A. Comparison of CDR H3

344 interactions of ADI-62113 and COVA1-16 with the RBD. White, SARS-CoV-2 RBD; green, ADI-

345 62113; cyan, COVA1-16. The ${ }_{99} \mathrm{YYDRxG}_{100 \mathrm{~d}}$ hexapeptide is highlighted to show the conserved

346 structure in CDR H3 interacting with the RBD. B. The YYDRxG motif is located at the tip of CDR

$347 \mathrm{H} 3$ and precedes a G1 $\beta$-bulge in the descending strand of the hairpin structure . Residues in the

$348 \beta$-turn at the tip of CDR $\mathrm{H} 3$ are numbered $\mathrm{i}$ to $\mathrm{i}+3$ (magenta). The $\mathrm{V}_{\mathrm{H}} \mathrm{D} 100 \mathrm{a}$ carboxyl hydrogen

349 bonds to backbone amides of $\mathrm{V}_{\mathrm{H}} \mathrm{R} 100 \mathrm{c}(\mathrm{i}+2)$ and $\mathrm{V}_{\mathrm{H}} \mathrm{Y} 100 \mathrm{e}$. *indicates somatically mutated

350 residue. C. Backbone comparison of an inserted $\beta$-bulge versus a standard $\beta$-strand in a $\beta$-sheet.

351 Schematic backbones show the $\beta$-harpin in ADI-62113 CDR H3 that contains a G1 $\beta$-bulge

352 following the glycine residue $(i+3)$ in the $\beta$-turn and comparison with a standard $\beta$-hairpin also

353 with a type $1 \beta$-turn at its tip (PDB ID: 4H5U). Amino-acid side chains are simplified as gold 
bioRxiv preprint doi: https://doi.org/10.1101/2021.12.15.472864; this version posted December 17,2021 . The copyright holder for this preprint

(which was not certified by peer review) is the author/funder, who has granted bioRxiv a license to display the preprint in perpetuity. It is made available under aCC-BY-NC-ND 4.0 International license.

354 spheres. Arrows indicate the register change between the two motifs due to an additional residue

355 in the $\beta$-hairpin in ADI-62113. D. Limited space between residue $V_{H}$ G100d and RBD favors a

356 glycine residue at this position in the $\beta$-bulge. A hydrogen bond is formed between the $V_{H} G 100 d$

357 carbonyl oxygen and S383 hydroxyl in the RBD. A $\pi-\pi$ interaction is formed between $V_{H} Y 100$ and

358 the peptide backbone of ${ }_{382} \mathrm{VS}_{383}$ of SARS-CoV-2 RBD. 
A

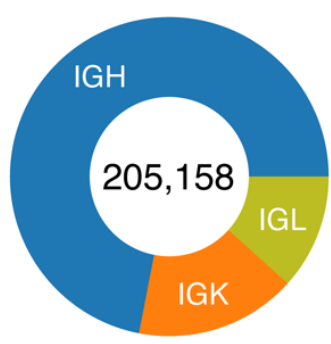

Library Seqences
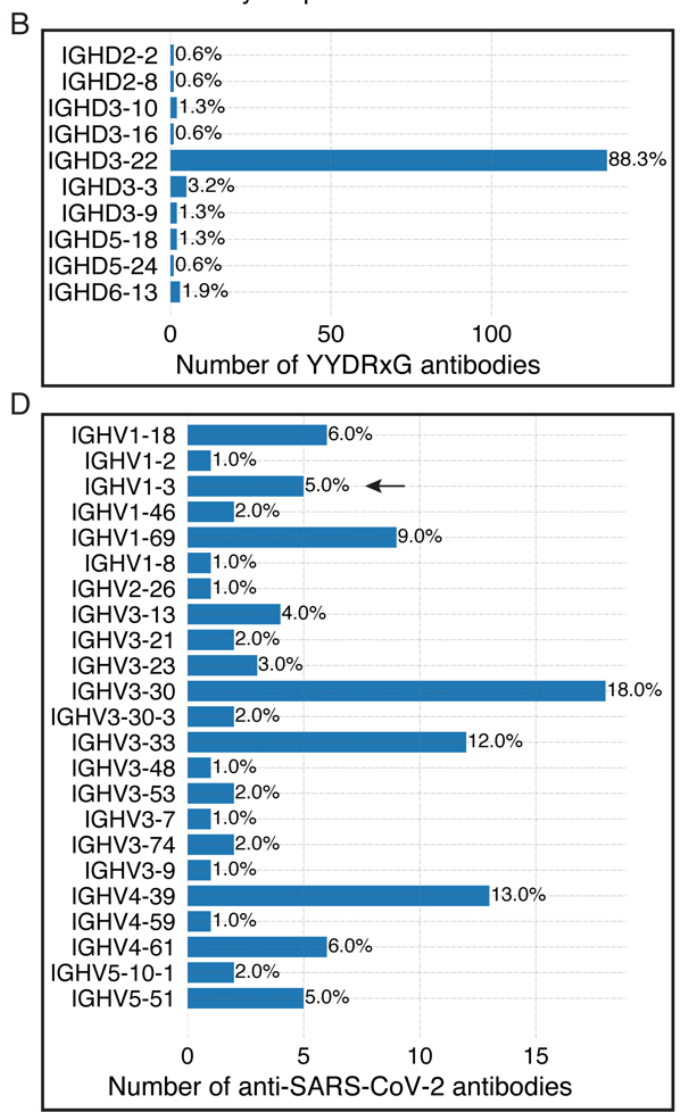

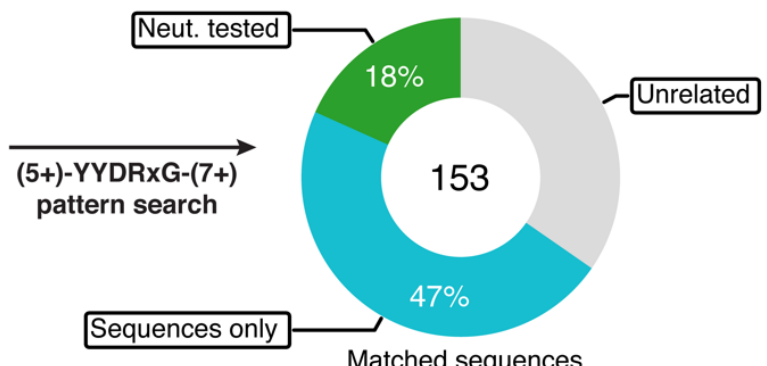

Matched sequences

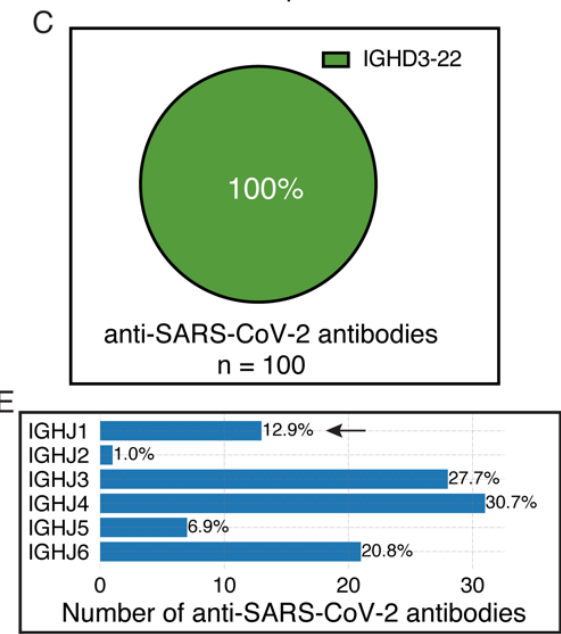

360 Figure 3. A YYDRxG pattern search identifies SARS-CoV-2 cross-neutralizing antibodies.

361 A. Over 205,000 publicly available antibody sequences were retrieved from GenBank and

362 supplementary files of previous publications reporting human anti-SARS-CoV-2 antibodies. The

363 compiled antibody sequence library consists of $72 \%$ heavy chains, $16.4 \%$ kappa chains, and $11.7 \%$

364 lambda chains. CDR3 amino-acid sequences were used to search for the YYDRxG motif with five

365 or more amino acid residues prior and seven or more amino acid posterior to the hexad motif.

366153 heavy chain sequences were identified that contain a YYDRxG pattern and followed by data 
367 curation with literature review. $66 \%(n=100)$ are antibodies isolated from COVID-19 patients and

368 mRNA vaccinees. 28 (18\%) have been validated for SARS-CoV-2 neutralization (Neut. Tested),

369 while $82(47 \%)$ have not (sequences only). B. YYDRxG antibodies are mostly encoded by the

370 IGHD3-22 gene. All of the D genes used by YYDRxG antibodies were counted. Numbers at the

371 right side of each bar indicate the percent of the total of identified YYDRxG antibodies. C. IGHD3-

37222 encodes all YYDRxG antibodies against SARS-CoV-2. All 110 sequences of anti-SARS-CoV-

3732 antibodies were analyzed and counted. D-E. Heavy chain variable (D, IGHV) and joining (E,

374 IGHJ) genes of YYDRxG antibodies isolated from COVID-19 patients or vaccinees. A diverse but

375 limited set of variable and joining genes pairs with IGHD3-22 in YYDRxG antibodies against

376 SARS-CoV-2. IGHV3-30, IGHV4-39, IGHV3-33, and IGHV1-69 are more frequently found than

377 others. Arrows indicates the immunoglobulin genes that encode ADI-62113 in this study. 

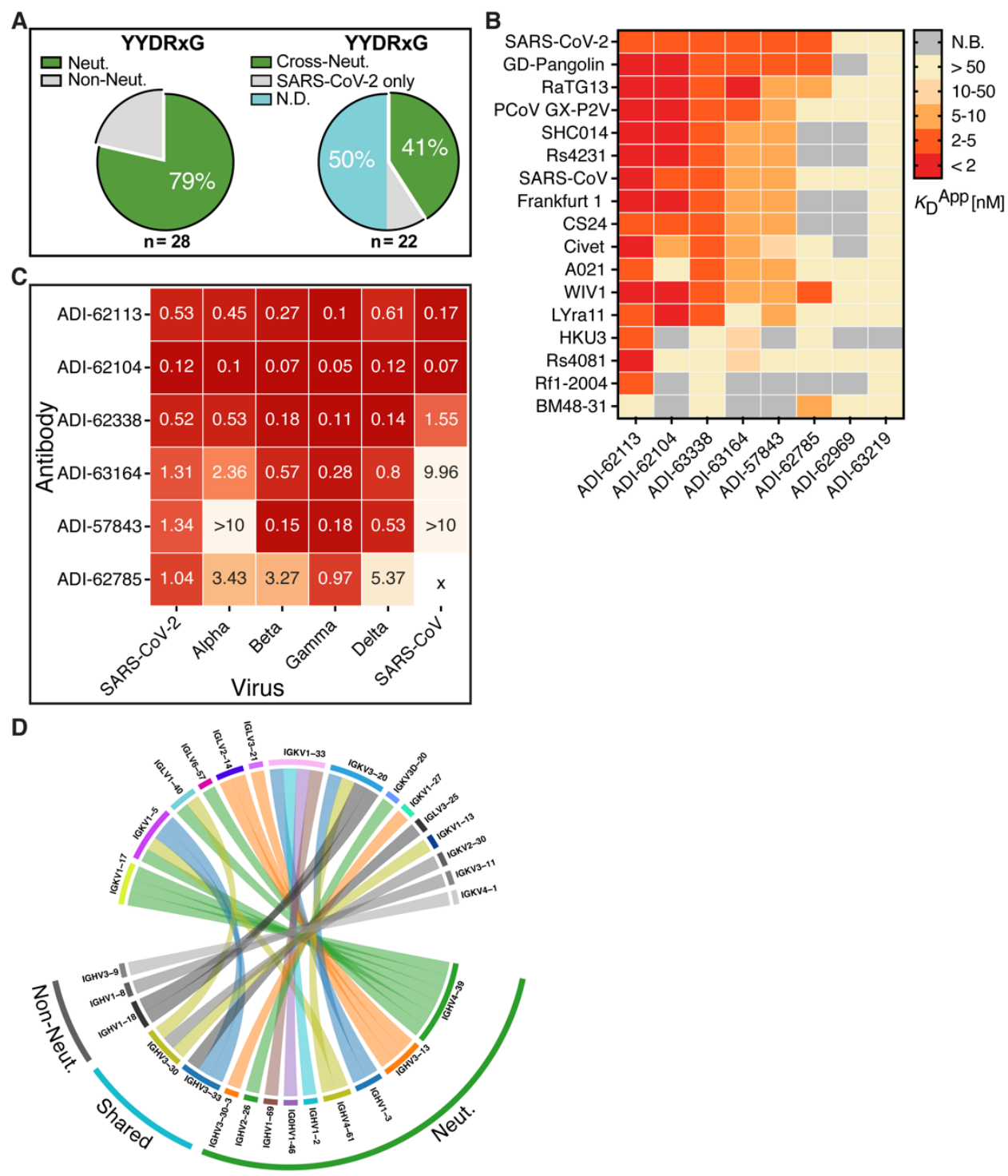

Figure 5. The YYDRXG motif is associated with potent and broad neutralization. A.

394 Neutralization overview of YYDRxG antibodies against SARS-CoV-2. Antibodies with

395 neutralization data available from previous publications or this study are included in this analysis.

396 Within 28 YYDRxG antibodies, 22 (79\%) exhibit neutralization (Neut.) against SARS-CoV-2 (left).

397 Among these 22 antibodies, 9 (41\%) cross-neutralize (Cross-Neut.) SARS-CoV, while 2 (9\%) do

398 not (SARS-CoV-2 only); another 11 (50\%) have not been tested against SARS-CoV (N.D.) (right).

399 B. Cross-reactivity of ADI antibodies with a YYDRxG motif across sarbecoviruses. ADI antibodies

400 were titrated with sarbecovirus RBDs expressed on the yeast surface. Color bars indicated 
401 apparent binding affinities ( $\left.K_{\mathrm{D}}^{\mathrm{App}} \mathrm{S}\right)$ as indicated in the key. Red indicates strong binding, yellow

402 indicates weak binding, and gray indicates no detectable binding (N.B.). Most antibodies are

403 cross-reactive with many other sarbecovirus RBDs, except for ADI-63219 and ADI62969. ADI-

40462113 showed the broadest spectrum of cross-reactivity to other sarbecoviruses. Titration curves

405 used to determine binding affinities are shown in Figure S5. C. ADI antibodies neutralize SARS-

406 CoV-2 VOCs and SARS-CoV. Neutralization was tested using a pseudovirus assay system.

407 Neutralization potency, i.e. $I_{50}$, for each antibody against corresponding viruses are shown on a

408 heatmap with red indicating potent neutralization. ADI-63219 and ADI-62969 showed no

409 neutralization to SARS-CoV-2 (Figure S7) and are not included in this heatmap. X indicates no

410 neutralization activity detected in the pseudovirus assay. D. Distinct combinations of heavy and

411 light variable genes used by neutralizing and non-neutralizing antibodies. Circos plot showing

412 combinations of heavy and light chain variable genes in each encoded antibody. Colored ribbons

413 represent variable genes encoding neutralizing antibodies (Neut.) while gray indicate non-

414 neutralizing antibodies (Non-Neut.). IGHV3-30, IGHV3-33, and IGKV3-20 were found in both

415 neutralizing and non-neutralizing antibodies. YYDRxG antibodies against SARS-CoV-2 with

416 neutralization data available are included in this analysis $(n=28)$. Antibody names and CDR H3

417 sequences of these antibodies are included in Table S2. 

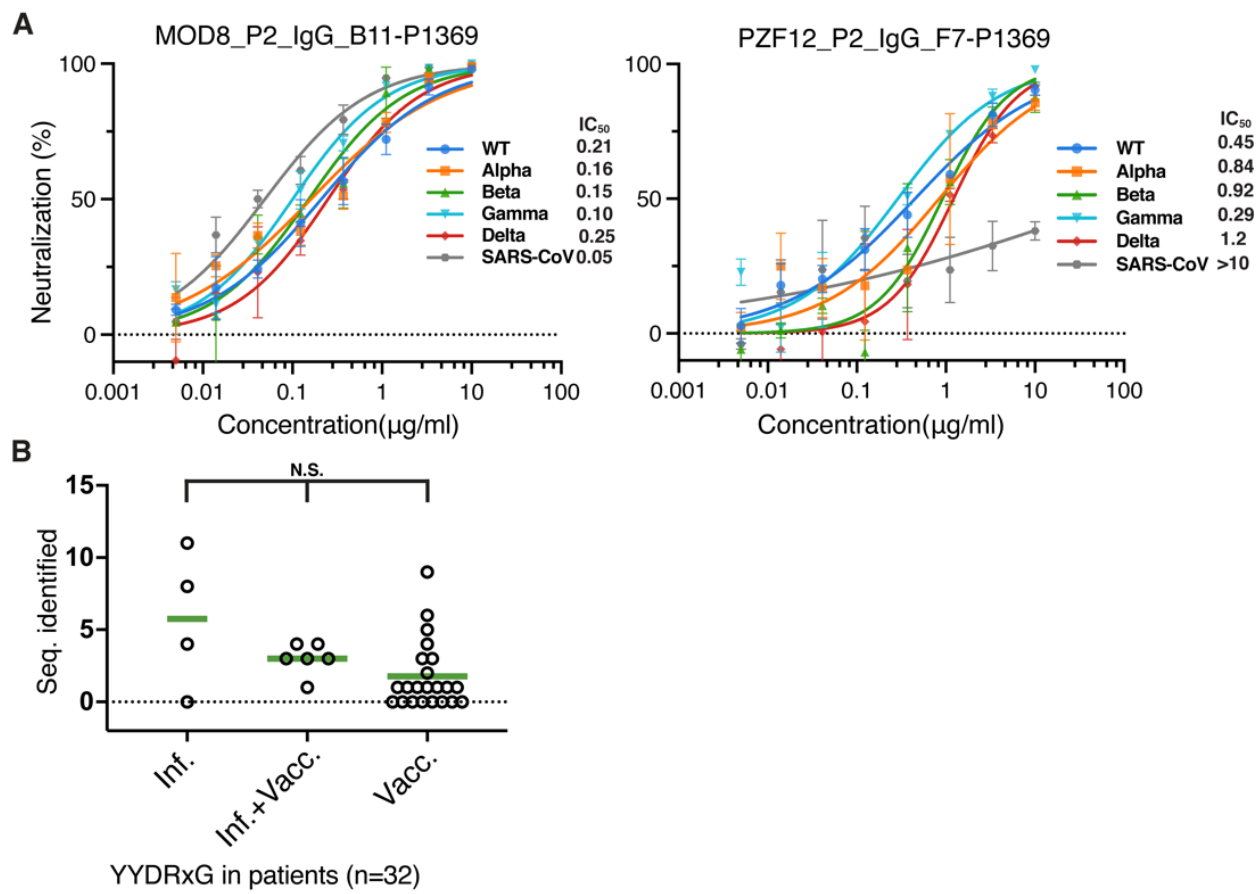

419 Figure 6. The YYDRxG pattern search identifies broad and potent antibodies to

420 sarbecoviruses. A. Representative antibodies show potent neutralization. MOD8_P2_lgG_B11-

421 P1369 and PZF12_P2_IgG_F7-P1369, were selected from the 83 sequences, which do not have

422 any neutralization data available. The two antibodies were cloned, expressed, purified, and tested

423 against SARS-CoV-2, VOCs and SARS-CoV in pseudovirus neutralization assay. Neutralization

424 potency, i.e. $I_{50}$ S are shown in the right of each panel. B. YYDRxG antibodies sequenced from

425 COVID-19 and vaccinated patients. The number of YYDRxG antibody sequences identified in 426 each patient's antibodies (Seq. identified) were split into three groups according the medical

427 history reported in their original publication (Cho et al., 2021; Gaebler et al., 2021; Robbiani et al.,

428 2020; Z. Wang, J. C. C. Lorenzi, et al., 2021; Z. Wang, F. Muecksch, et al., 2021; Z. Wang, F.

429 Schmidt, et al., 2021). All antibody sequences $(n=17,536)$ sequenced from COVID-19 patients

430 without vaccination $(n=4)$, COVID-19 patients vaccinated post-recovery $(n=6)$, and vaccinees

431 without COVID-19 history $(\mathrm{n}=22)$ are included in this analysis. Non-parameter Kruskal-Wallis test 
432 was used to compare the number of YYDRxG antibodies isolated in each group. N.S., not

433 significant $(P>0.05)$. Sequence counts for each patient are included in Table S4.

\section{MATERIALS AND METHODS}

\section{Expression and purification of SARS-CoV-2 RBD}

436 The receptor-binding domain (RBD) (residues 333-529) of the SARS-CoV-2 spike (S) protein

437 (GenBank: QHD43416.1), was cloned into a customized pFastBac vector (Ekiert et al., 2011), 438 and fused with an N-terminal gp67 signal peptide and C-terminal His 6 tag (Yuan et al., 2020).

439 Recombinant bacmids encoding each RBDs were generated using the Bac-to-Bac system

440 (Thermo Fisher Scientific) followed by transfection into Sf9 cells using FuGENE HD (Promega) to

441 produce baculoviruses for RBD expression. RBD protein was expressed in High Five cells

442 (Thermo Fisher Scientific) with suspension culture shaking at 110 r.p.m. at $28^{\circ} \mathrm{C}$ for 72 hours

443 after the baculovirus transduction at an MOI of 5 to 10. Supernatant containing RBD protein was

444 then concentrated using a $10 \mathrm{kDa}$ MW cutoff Centramate cassette (Pall Corporation) followed by

445 affinity chromatography using Ni-NTA resin (QIAGEN) and size exclusion chromatography using

446 a HiLoad Superdex 200 pg column (Cytiva). The purified protein sample was buffer exchanged

447 into $20 \mathrm{mM}$ Tris- $\mathrm{HCl} \mathrm{pH} 7.4$ and $150 \mathrm{mM} \mathrm{NaCl}$ and concentrated for binding analysis and 448 crystallographic studies.

\section{Expression and purification of antibodies}

450 ADI-62113 lgG was produced in S. cerevisiae cultures, as previously described (Sakharkar et al., 451 2021). Briefly, yeast cultures were incubated at $30^{\circ} \mathrm{C}$ and $80 \%$ relative humidity, with shaking at $452650 \mathrm{rpm}$. Following 6 days of incubation, yeast cultures were cleared by centrifugation, and 453 resultant supernatant containing IgG was purified by protein A chromatography. Bound lgGs were 454 eluted from protein A resin using $200 \mathrm{mM}$ acetic acid with $50 \mathrm{mM} \mathrm{NaCl}(\mathrm{pH} 3.5)$ diluted into 1/8 
$455[\mathrm{v} / \mathrm{v}] 2$ M HEPES (pH 8.0) and subsequently buffer-exchanged into PBS (pH 7.0). Additional

456 YYDRxG motif-containing monoclonal antibodies were produced with the same method for

457 characterization by sarbecovirus RBD yeast surface display and neutralization assays. ADI-

45862113 Fab fragments for structural studies were generated by papain digestion for 2 hours at 30

$459{ }^{\circ} \mathrm{C}$, and the reaction was terminated by addition of iodoacetamide. Fab fragments were purified

460 over Protein A resin to remove cleaved Fc fragments and undigested IgG. The flowthrough was

461 then purified over CaptureSelect ${ }^{\mathrm{TM}} \operatorname{lgG}-\mathrm{CH} 1$ affinity resin (ThermoFisher Scientific), and bound

462 Fab fragments eluted with $200 \mathrm{mM}$ acetic acid with $50 \mathrm{mM} \mathrm{NaCl}(\mathrm{pH}$ 3.5) diluted into 1/8 [v/v] 2

463 M HEPES (pH 8.0) before buffer exchanging into PBS (pH 7.0). Expression plasmids encoding

464 the heavy (HC) and light chains (LC) of Seq8 (MOD8_P2_lgG_B11-P1369) and Seq10

465 (PZF12_P2_IgG_F7-P1369) were transiently co-transfected into ExpiCHO cells at a ratio of 2:1

466 (HC:LC) using ExpiFectamine ${ }^{\mathrm{TM}} \mathrm{CHO}$ Reagent (Thermo Fisher Scientific) according to the

467 manufacturer's instructions. The supernatant was collected at 10 days post-transfection. The lgG

468 antibodies and Fabs were purified with a CaptureSelect ${ }^{\mathrm{TM}} \mathrm{CH} 1-\mathrm{XL}$ Matrix column (Thermo Fisher

469 Scientific) for affinity purification and a HiLoad Superdex 200 pg column (Cytiva) for size exclusion

470 chromatography. The purified Fab protein samples were buffer exchanged into $20 \mathrm{mM}$ Tris- $\mathrm{HCl}$

$471 \mathrm{pH} 7.4$ and $150 \mathrm{mM} \mathrm{NaCl}$ and concentrated for crystallographic studies and the IgG proteins used

472 for binding and neutralization assays.

\section{YYDRxG pattern search}

474 Over 205,000 antibody sequences including heavy and light chains were retrieved from GenBank

475 using Biopython program (Cock et al., 2009), supplemented with sequences reported in previous

476 publications (Cho et al., 2021; Gaebler et al., 2021; Robbiani et al., 2020; Z. Wang, J. C. C.

477 Lorenzi, et al., 2021; Z. Wang, F. Muecksch, et al., 2021; Z. Wang, F. Schmidt, et al., 2021), and

478 then subjected to repertoire analysis using PyIR program (Soto et al., 2020) implemented with 
479 IgBLAST (Ye et al., 2013). CDR H3 amino-acid sequences from the compiled dataset were

480 subjected to computational pattern search. Key residues in ADI-62113 and COVA1-16 interacting

481 with SARS-CoV-2 RBD were analyzed using their crystal structures with SARS-CoV-2 RBD.

482 YYDRxG and homologue sequences were used for the computational search. A length restriction

483 with five or more amino acids prior and seven or more amino acids post YYDRxG key residues

484 according to the structure analysis of ADI-62113 and COVA1-16 in complex with RBD was

485 included in the search, which automatically yield a length restriction of $>18$ aa in CDR H3 that

486 likely positions the YYDRxG motif to protrude towards the RBD surface. This constraint was thus

487 defined along with the YYDRxG pattern to search for matches in compiled CDR H3 datasets.

488 Genbank accession identifiers of the resultant YYDRxG hits were used for retrieving the full

489 sequence record from Genbank. The compiled data were analyzed manually with sequence

490 check and literature curation. Sequences of the antibodies against SARS-CoV-2 were included in

491 further analysis.

\section{Sequence analysis and surface conservation}

493 Sequences of sarbecoviruses were retrieved from GenBank using Biopython program, aligned

494 using MUSCLE program (Edgar, 2004) built in European Bioinformatics Institute (EBI) web

495 services (Madeira et al., 2019) and scored for surface conservation in ConSurf server (Ashkenazy

496 et al., 2016; Landau et al., 2005). The conserved surface of SARS-CoV-2 RBD was visualized

497 using the PyMOL program (Schrödinger, LLC). For visualization purpose, representative

498 sarbecovirus RBD sequences from three clades were selected to compare with the conserved

499 ADI-62113 epitope residues. BM48-31, YP_003858584; bat-Rf1-2004, ABD75323; PCoV_GX-

500 P5L, QIA48632; PCoV_GX-P2V, QIQ54048; RaTG13, QHR63300; SARS-CoV-2,

501 YP_009724390; A021-SARS-CoV-2, QWQ56573; bat-Rs4081, ATO98120; GD-pangolin,

502 QLR06866; bat-LYRa11, AHX37558; civet010, AAU04649; SARS-CS24, ABF68959; bat-HKU3- 
1, AAY88866; SARS-CoV-Tor2, YP_009825051; Frankfurt 1, AAP33697; Rs4231, ATO98157;

504 WIV1, AGZ48828; SHC014, QJE50589. Antibody sequences were also aligned using the same

505 method and visualized using ESPript 3.0 server (Robert \& Gouet, 2014).

\section{Crystallization and X-ray structure determination}

507 The ADI-62113 Fab was mixed with SARS-CoV-2 RBD in an equimolar ratio and incubated 508 overnight at $4^{\circ} \mathrm{C} .384$ conditions of the JCSG Core Suite (Qiagen) were used for setting-up trays

509 for screening at a concentration of $11.9 \mathrm{mg} / \mathrm{ml}$ on our robotic CrystalMation system (Rigaku) at

510 Scripps Research. Crystallization trials were set-up by the vapor diffusion method in sitting drops

511 containing $0.1 \mu \mathrm{l}$ of protein complex and $0.1 \mu \mathrm{l}$ of reservoir solution. Crystals appeared on day 2 ,

512 were harvested on day 14, and flash cooled and stored in liquid nitrogen until data collection.

513 Diffraction data were collected at cryogenic temperature (100 K) at the Stanford Synchrotron

514 Radiation Lightsource (SSRL) on Scripps/Stanford beamline 12-1 with a beam wavelength of

$5150.97946 \AA$, and processed with HKL2000 (Otwinowski \& Minor, 1997). Diffraction data were

516 collected from crystals grown in a drop containing $0.08 \mathrm{M}$ sodium acetate $\mathrm{pH} 4.6,0.16 \mathrm{M}$

517 ammonium sulfate, $20 \%(\mathrm{w} / \mathrm{v})$ polyethylene glycol 4000, and 20\% (v/v) glycerol. The X-ray

518 structure was solved by molecular replacement (MR) using PHASER (McCoy et al., 2007) with

519 MR models for the RBD and Fab from PDB 7JMW (Liu et al., 2020). Iterative model building and

520 refinement were carried out in COOT (Emsley \& Cowtan, 2004) and PHENIX (Acta

521 Crystallographica Section D: Biological CrystallographyAdams et al., 2010), respectively. Epitope

522 and paratope residues, as well as their interactions, were identified with the PISA program

523 (Krissinel \& Henrick, 2007) using calculated buried surface area (BSA >0 $\AA^{2}$ ) as the criterion.

\section{Binding to sarbecovirus RBDs via yeast surface display}

525 To assess binding breadth, IgGs and recombinant human Fc-conjugated hACE2 (Sino Biological, 526 10108-H02H) were tested against the panel of 17 sarbecovirus RBDs expressed by yeast display 
527 as previously described (Rappazzo et al., 2021). Briefly, EBY100 yeast were transformed with a

528 plasmid encoding the yeast mating protein Aga2p linked to sarbecovirus RBD on the $\mathrm{C}$ terminus.

529 To induce RBD expression, $0.5 \mathrm{OD}_{600} / \mathrm{ml}$ of yeast were transferred to SGCAA media and cultured

530 at $20^{\circ} \mathrm{C}$ for $16-20$ hours with $180 \mathrm{rpm}$ shaking. Next, IgGs and hACE2 were titrated via 3-fold

531 serial dilutions from $100 \mathrm{nM}$ to $0.5 \mathrm{pM}$. RBD-expressing cells were aliquoted into 96-well plates

532 and incubated with $100 \mu \mathrm{l}$ of $100 \mathrm{nM} \operatorname{lgG}$ for 30 minutes on ice. Next, cells were washed twice

533 with PBSF (1X PBS, 0.1\% BSA) before secondary detection with 1:100 dilutions of APC-

534 conjugated mouse anti-hemagglutinin tag (HA).11 antibody (BioLegend, 901524), PE-conjugated

535 goat anti-human IgG polyclonal antibodies (Southern Biotech, 2040-09), and propidium iodide

536 (Invitrogen, P1304MP) for 20 minutes on ice. Cells were washed twice with PBSF before

537 analyzing via flow cytometry on a BD FACS Canto II (BD Biosciences). Binding curves were fitted

538 with four-parameter non-linear regression analysis to calculate the apparent equilibrium binding

539 constant $\left(K_{\mathrm{D}}^{\mathrm{App}}\right)$ in GraphPad Prism 9. Points exhibiting hook effects at higher concentrations

540 were excluded from analysis.

\section{Pseudovirus production and neutralization assays}

542 Plasmids encoding SARS-CoV, SARS-CoV-2, or other variants of the spike protein, with the ER

543 retrieval signal removed were co-transfected with MLV-gag/pol and MLV-CMV-Luciferase

544 plasmids into HEK293T cells to generate pseudoviruses. Lipofectamine 2000 (Thermo Fisher

545 Scientific, 11668019) was used according to the manufacturer's instructions. The cell culture

546 supernatants containing S-pseudotyped MLV virions were collected at 48 hours post transfection,

547 filtered through a $0.22 \mu \mathrm{m}$ membrane and stored at $-80^{\circ} \mathrm{C}$ until use. Lentivirus transduced Hela

548 cells expressing hACE2 (GenBank: BAB40370.1) were enriched by fluorescence-activated cell

549 sorting (FACS) using biotinylated SARS-CoV-2 RBD conjugated with streptavidin-Alexa Fluor 647

550 (Thermo, S32357). Stable cell lines with consistent and high hACE2 expression levels were 
551 established as HeLa-hACE2 and used in the pseudovirus neutralization assay. Monoclonal

552 antibody IgGs were serially diluted with DMEM medium supplemented with $10 \%$ heat-inactivated

553 FBS, 1\% Q-max, and 1\% P/S. $25 \mu \mathrm{l}$ of 3-fold serial dilutions were incubated with $25 \mu \mathrm{l}$ of

554 pseudotyped viruses at $37^{\circ} \mathrm{C}$ for 1 hour in 96-well half-well plate (Corning, 3688). Right before

555 the end of the incubation, HeLa-hACE2 cells were suspended with culture medium at a 556 concentration of $2 \times 105 / \mathrm{ml}$. The DEAE-dextran (Sigma, 93556-1G) was added to the cell solutions

557 at $20 \mu \mathrm{g} / \mathrm{m}$ for enhanced infectivity. $50 \mu \mathrm{l}$ of the cell solution was distributed into each well. The

558 supernatant was removed 48 hours post incubation at $37^{\circ} \mathrm{C}$, and the neutralization efficiency was

559 calculated by measuring the luciferase levels in the HeLa-hACE2 cells. Cells were washed and

560 lysed in luciferase lysis buffer (25 mM Gly-Gly pH 7.8, $15 \mathrm{mM} \mathrm{MgSO}_{4}, 4 \mathrm{mM}$ EGTA, 1\% V/N Triton

$561 \mathrm{X}-100)$ at room temperature for 10-20 mins. After addition of Bright-Glo (Promega, PR-E2620)

562 according to the manufacturer's instruction, luminescence signal was measured in duplicate. At

563 least two biological replicates were performed for neutralization assays with SARS-CoV-2, SARS-

564 CoV-2 variants of concern, and SARS-CoV. The IgG half-maximal inhibitory concentration $\left(\right.$ IC $\left._{50}\right)$

565 values were calculated using "One Site - Fit LogIC50" regression in GraphPad Prism 9. 
A
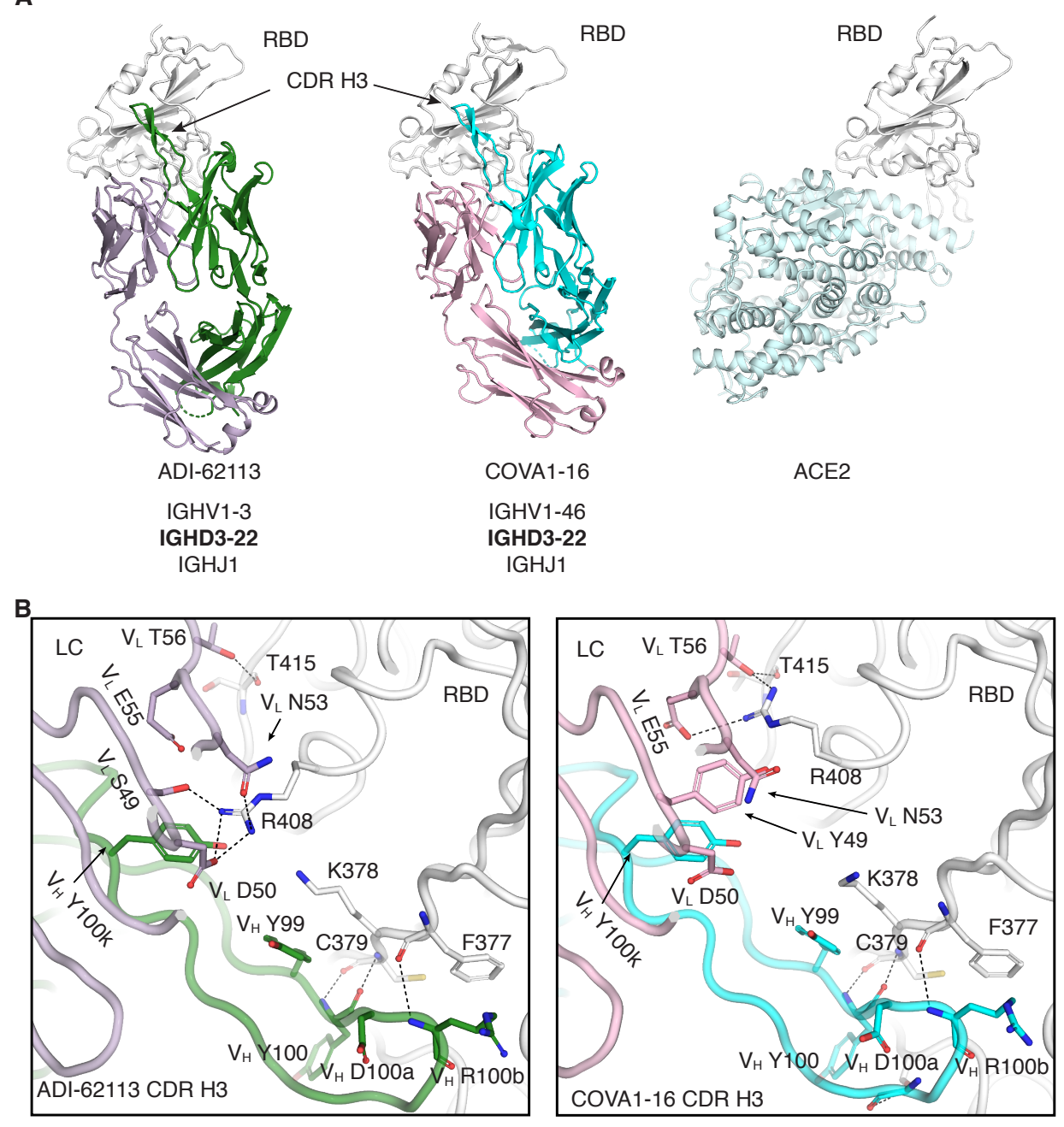

568 Figure S1. Structural comparison of ADI-62113 and COVA1-16. A. A similar binding mode to

569 SARS-CoV-2 RBD was found for ADI-62113 and COVA1-16. Structures are shown in ribbon

570 representation. Both antibodies compete with ACE2 binding as shown in the far right even

571 although their epitopes do not directly overlap with ACE2. SARS-CoV-2 RBD is shown in white.

572 The same perspective view was used for all structures. The $\beta$-hairpin in CDR H3 is more twisted

573 compared to the strands in the $\beta$-sheet in the core region of the Fab. Heavy chain immunoglobulin

574 genes are shown under each antibody for comparison. Both antibodies use the IGHD3-22 gene 
575 encoding the YYDRxG motif. B. Comparison between ADI-62113 and COVA1-16 Fab binding to

576 SARS-CoV-2 RBD. ADI-62113 adopts a similar binding mode to COVA1-16. A long CDR H3

577 containing the YYDRxG motif dominates the binding to SARS-CoV-2. Some differences in

578 detailed interactions are seen due to sequence variation between the different antibodies, e.g.

579 interaction with R408 of the RBD. The structures are shown in backbone tube representation with

580 the side chains of residues involved in antibody-antigen interaction in sticks. 

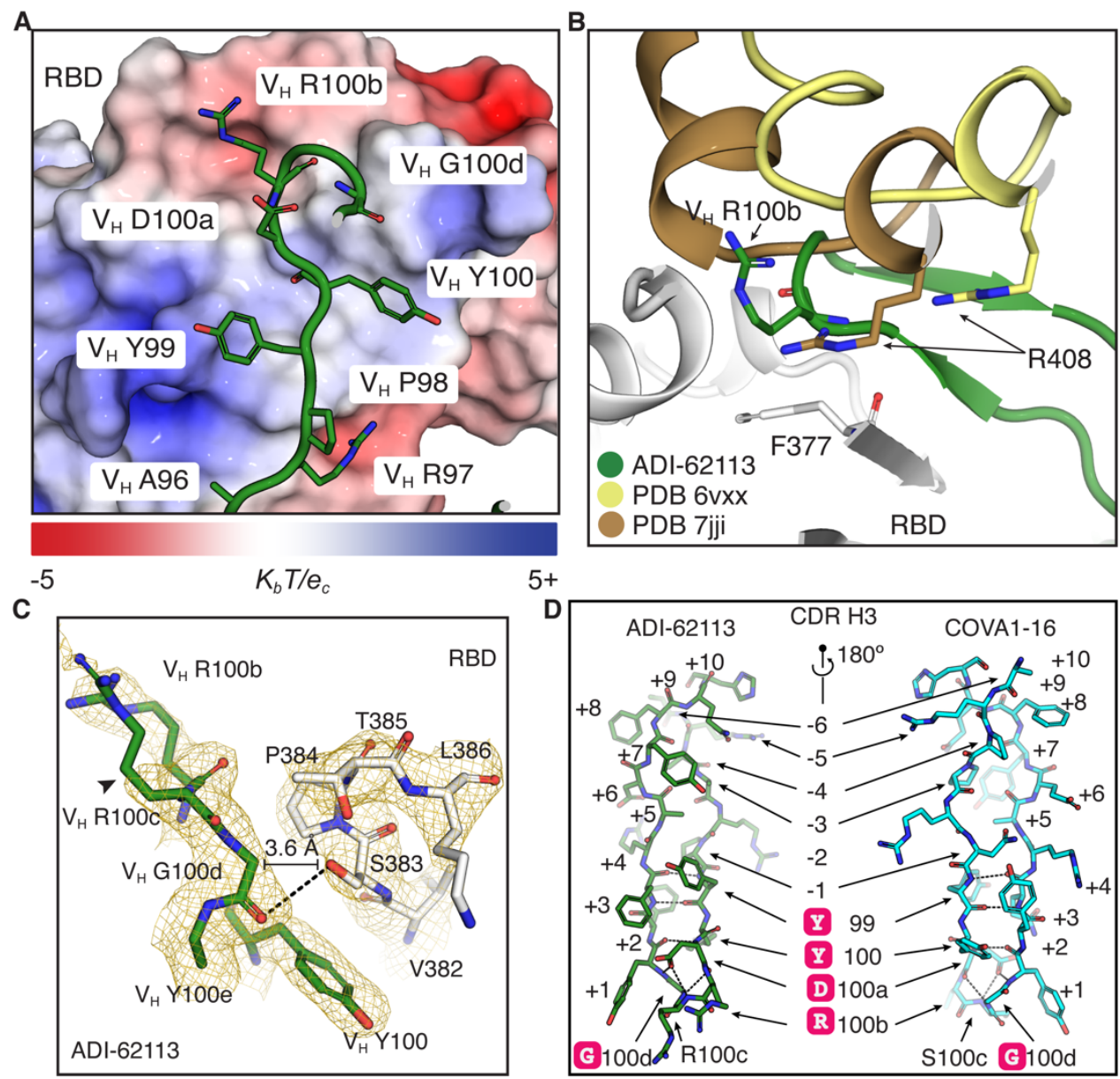

Figure S2. YYDRxG motif analysis A. CDR H3 of ADI-62113 bound to SARS-CoV-2 RBD surface. SARS-CoV-2 RBD is shown in an electrostatic surface representation. Red indicates a negatively charged surface and blue indicates a positively charged surface. The bar below the panel shows the electrostatic scale. CDR H3 is shown in a backbone tube representation with side chains in sticks. $V_{H} R 100 b$ binds to a recessed surface on the RBD with an overall negative charge. B. The conserved surface where $V_{H} R 100 b$ binds is also part of the interface between spike protomers when RBD is in the down conformation. Intra-protomer interaction among RBDs

589 within a spike is variable due to slight differences among RBD conformations in different 590 structures. Spikes with all RBD in "down" state are shown using two PDB IDs: 6VXX and 7JJI. 591 R408 from the neighboring RBD can bind to the same site where $V_{H} R 100 b$ in $A D I-62113$ and 
592 COVA1-16 binds. Interaction between an arginine and F377 also seems to be common for both

593 intra-protomer binding and antibody recognition at this site. C. Electron density around ADI-62113

$594 V_{H}$ R100c. The electron density map is contoured at $\sigma=1.0$ using a 2 mFo-DFc map calculated

595 from the structure factors using PHENIX program (Acta Crystallographica Section D: Biological

596 CrystallographyAdams et al., 2010). The $\mathrm{V}_{H} \mathrm{R} 100 \mathrm{c}$ has poor to no side-chain density likely due

597 to high mobility (indicated by an arrowhead). D. Comparison of the shared features of YYDRxG

598 in ADI-62113 and COVA1-16. The hydrogen bonding observed with the YYDRxG hexapeptide

599 are almost identical, indicating a conserved structure of the two CDR H3s. Sequences outside of

600 YYDRxG are highly variable and two proline substitutions (at positions -3 and -4 ) have no impact

601 on the YYDRxG conformation. The distance between YYDRxG to the first and last residue of

602 CDR H3 seems important to position the hexapeptide at the tip of CDR H3 for RBD binding. A

603 minimum of 5+ aa prior and 7+aa post YYDRxG hexapeptide should allow formation of a similar

604 CDR H3 structure. 


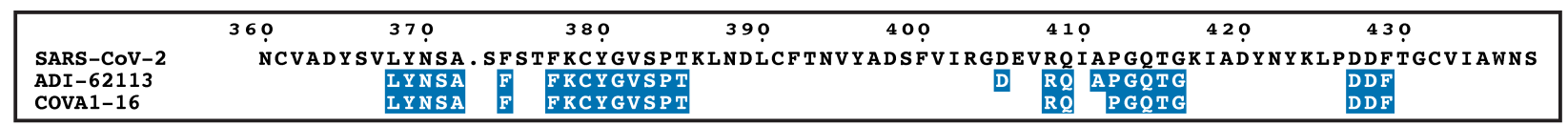

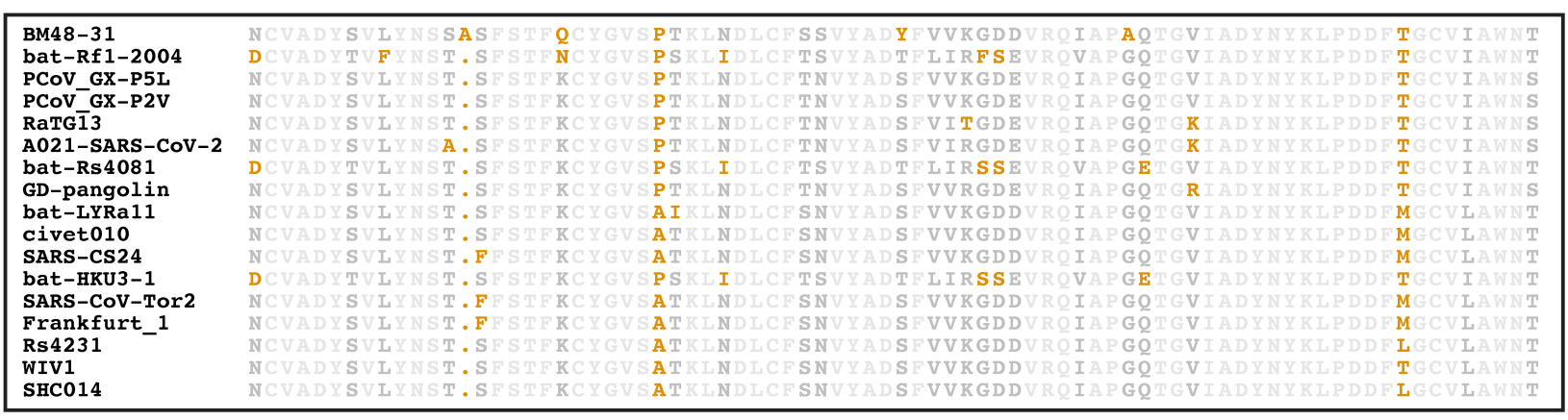

606 Figure S3. Conserved epitope residues of YYDRxG antibodies. Epitope residues of ADI-

60762113 and COVA1-16, two YYDRxG antibodies, are highly conserved across sarbecoviruses.

608 Epitope residues are highlighted on the sequence of SARS-CoV-2 RBD in the upper panel.

609 Epitope residues are defined by having the buried surface area (BSA) by the indicated antibody

610 with $\mathrm{BSA}>0 \AA^{2}$ as the criterion. Other representative sarbecovirus sequences are aligned in the

611 lower panel. Conserved residues are shown in brown, variable in brown. RBD amino-acid

612 sequences were retrieved from GenBank database with the following IDs: BM48-31,

613 YP_003858584; bat-Rf1-2004, ABD75323; PCoV_GX-P5L, QIA48632; PCoV_GX-P2V,

614 QIQ54048; RaTG13, QHR63300; SARS-CoV-2, YP_009724390; SARS-A021, QWQ56573; bat-

615 Rs4081, ATO98120; PCOV-GD, QLR06866; bat-LYRa11, AHX37558; civet010, AAU04649;

616 SARS-CS24, ABF68959; bat-HKU3-1, AAY88866; SARS-CoV-Tor2, YP_009825051; Frankfurt

617 1, AAP33697; Rs4231, ATO98157; WIV1, AGZ48828; SHC014, QJE50589. 

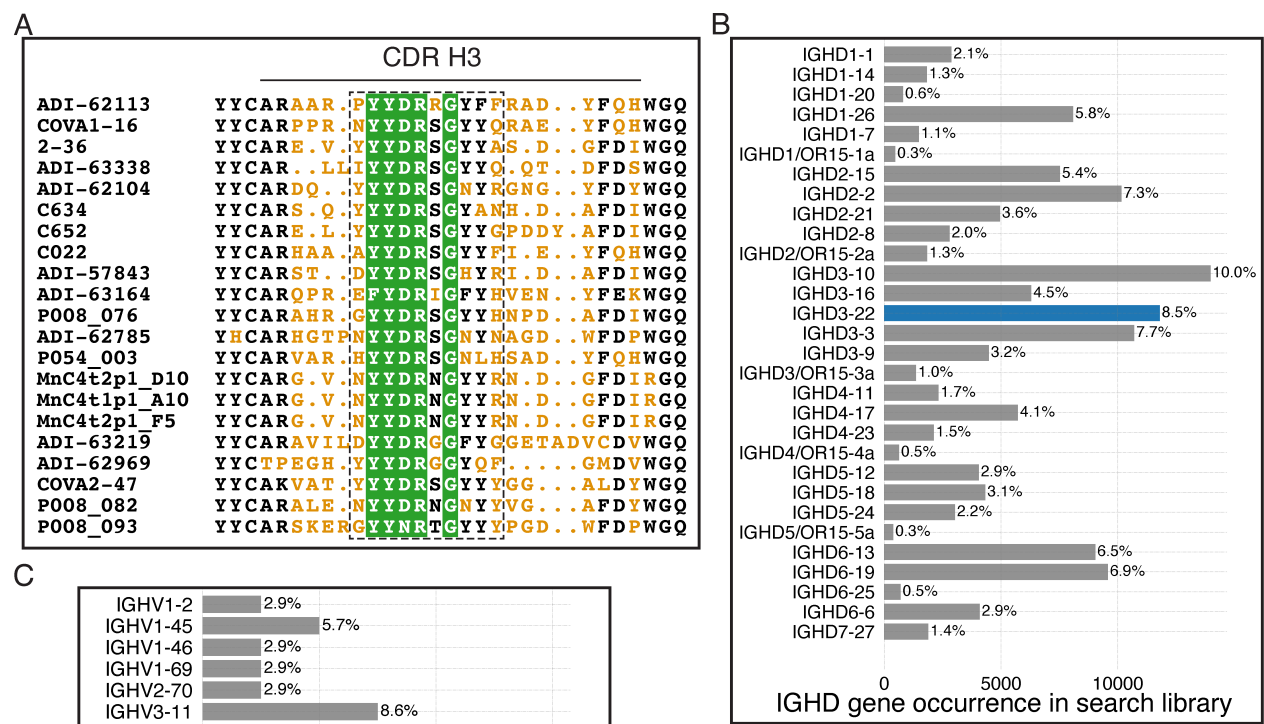

C

\begin{tabular}{|c|c|c|c|c|}
\hline IGHV1-2 & $2.9 \%$ & & & \\
\hline IGHV1-45 & & $5.7 \%$ & & \\
\hline IGHV1-46 & $2.9 \%$ & & & \\
\hline IGHV1-69 & $2.9 \%$ & & & \\
\hline IGHV2-70 & $2.9 \%$ & & & \\
\hline IGHV3-11 & & $8.6 \%$ & & \\
\hline IGHV3-23 & & & & $17.1 \%$ \\
\hline IGHV3-30 & $2.9 \%$ & & & \\
\hline IGHV3-30-3 & $2.9 \%$ & & & \\
\hline IGHV3-48 & & $5.7 \%$ & & \\
\hline IGHV3-7 & & $8.6 \%$ & & \\
\hline IGHV3-9 & $2.9 \%$ & & & \\
\hline $\begin{array}{l}\text { IGHV4-31 } \\
\text { IGHV4-34 }\end{array}$ & $2.9 \%$ & & & \\
\hline $\begin{array}{l}\text { IGHV4-34 } \\
\text { IGHV4-39 }\end{array}$ & & $5.7 \%$ & & \\
\hline $\begin{array}{r}\text { IGHV4-39 } \\
\text { IGHV4-4 }\end{array}$ & & $5.7 \%$ & & \\
\hline IGHV4-59 & & $5.7 \%$ & & \\
\hline IGHV4-61 & $2.9 \%$ & & & \\
\hline IGHV5-51 & & $5.7 \%$ & & \\
\hline $\mathrm{Nu}$ & of $u$ & ${ }_{\text {inrelated a }}^{2}$ & $\begin{array}{l}4 \\
\text { antibodies }\end{array}$ & 6 \\
\hline
\end{tabular}

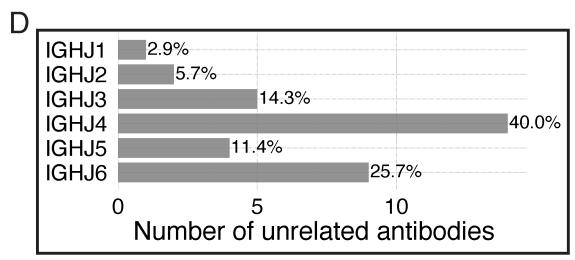

619 Figure S4. YYDRxG antibodies identified from the publicly available sequences. A. CDR H3

620 sequence alignment of representative YYDRxG antibodies against SARS-CoV-2. Conserved

621 residues are shown in black and white, and variable residues in orange. Green shades highlight

622 key residues in the YYDRxG motif. CDR H3 sequences for all antibodies are included in Table

623 S2 (tested against SARS-CoV-2) and Table S3 (sequence only). CDR H3 regions (IMGT definition)

624 are indicated by the solid line above the sequences. Sequences encoded by IGHD3-22 are boxed

625 with a dashed line. B. Immunoglobulin diversity (IGHD) genes in the computational search library

626 compiled with publicly available antibody sequences are described in Methods section. IGHD

627 genes are diversely distributed in the overall library. No single IGHD gene is dominant in the

628 antibody sequences, although some have higher propensity than others. IGHD3-22 encoding

629 YYDRxG antibodies is highlighted. C-D. Immunoglobulin variable (IGHV) and joining (IGHJ) 
bioRxiv preprint doi: https://doi.org/10.1101/2021.12.15.472864; this version posted December 17,2021 . The copyright holder for this preprint (which was not certified by peer review) is the author/funder, who has granted bioRxiv a license to display the preprint in perpetuity. It is made available under aCC-BY-NC-ND 4.0 International license.

630 genes in YYDRxG antibodies isolated from non-COVID-19 cohorts. The diverse sets of IGHV and

631 IGHJ genes are distinct from, but overlap with, those observed in anti-SARS-CoV2 antibodies. 
bioRxiv preprint doi: https://doi.org/10.1101/2021.12.15.472864; this version posted December 17, 2021. The copyright holder for this preprint (which was not certified by peer review) is the author/funder, who has granted bioRxiv a license to display the preprint in perpetuity. It is made available under aCC-BY-NC-ND 4.0 International license.
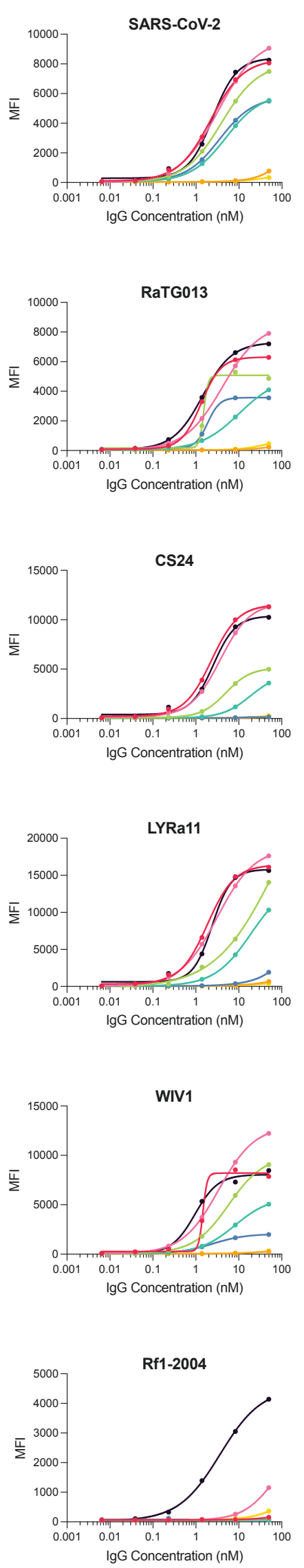
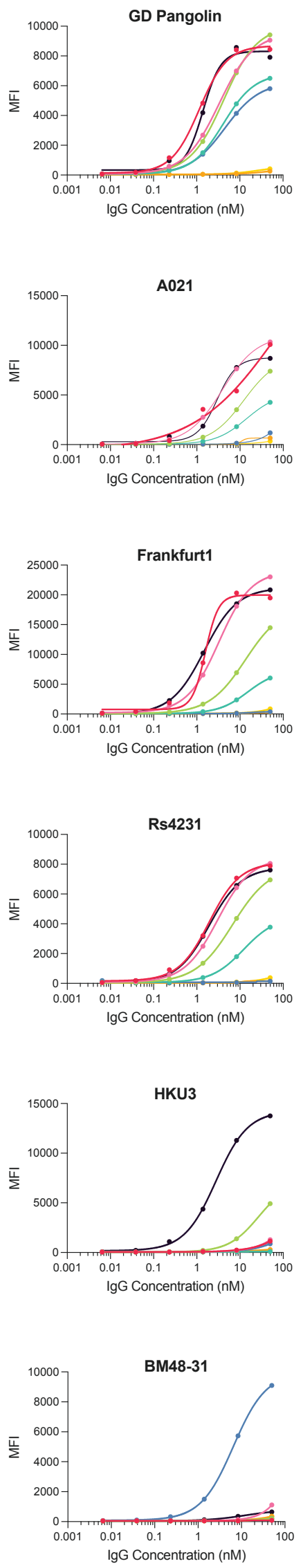
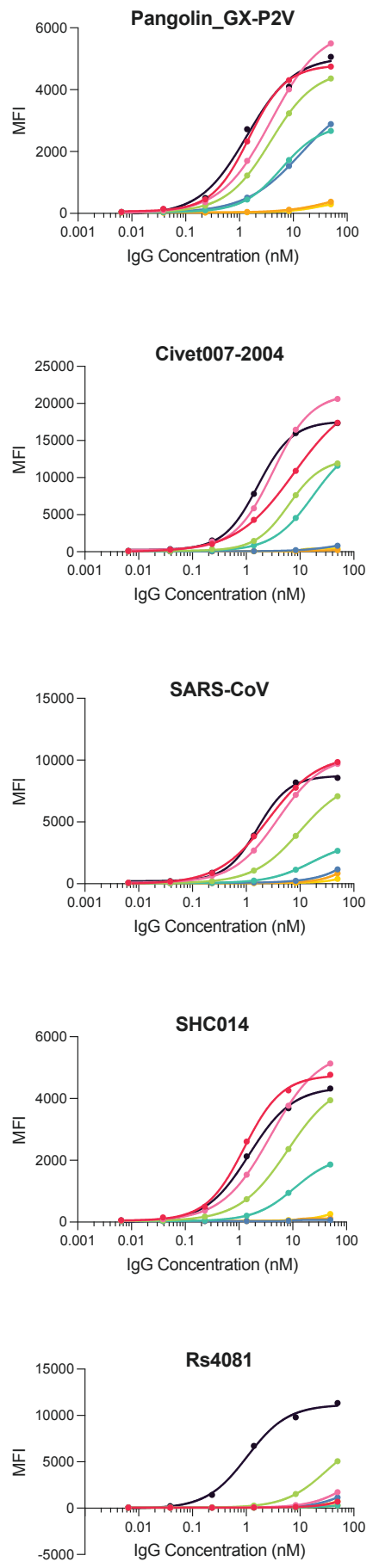

$$
\begin{aligned}
& \rightarrow \text { ADI-62113 } \\
& \rightarrow \text { ADI-62104 } \\
& \rightarrow \text { ADI-63338 } \\
& \rightarrow \text { ADI-63164 } \\
& \rightarrow \text { ADI-57843 } \\
& \rightarrow \text { ADI-62785 } \\
& \rightarrow \text { ADI-62969 } \\
& \rightarrow \text { ADI-63219 }
\end{aligned}
$$


bioRxiv preprint doi: https://doi.org/10.1101/2021.12.15.472864; this version posted December 17, 2021. The copyright holder for this preprint

(which was not certified by peer review) is the author/funder, who has granted bioRxiv a license to display the preprint in perpetuity. It is made available under aCC-BY-NC-ND 4.0 International license.

633 Figure S5. Cross-reactivity of YYDRxG antibodies with sarbecoviruses. ADI antibodies were

634 used for kinetic binding assay with sarbecovirus RBDs displayed on the yeast cell surface. Binding

635 affinities are plotted as a heatmap in Figure 5B. Most antibodies show potent binding to multiple

636 sarbecoviruses, except for ADI-62969 and ADI-63219. The CDR H3 length of these two

637 antibodies seems to be consistent with diminished binding to antigen. 
A

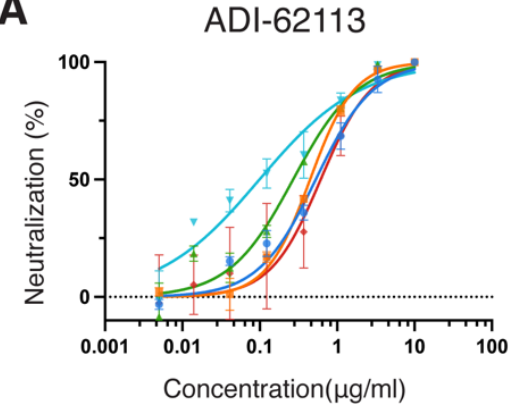

ADI-63164

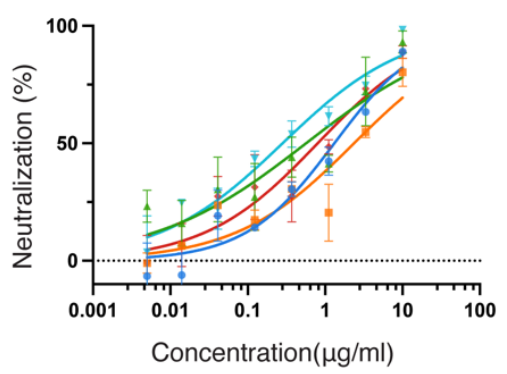

ADI-62969

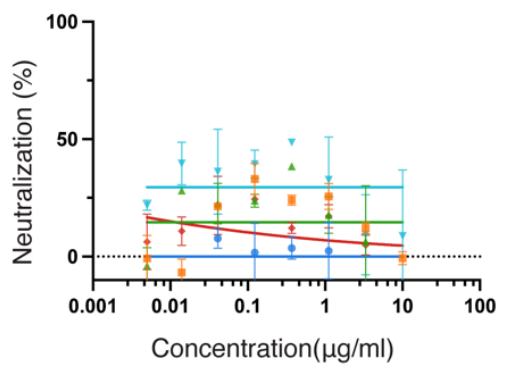

B

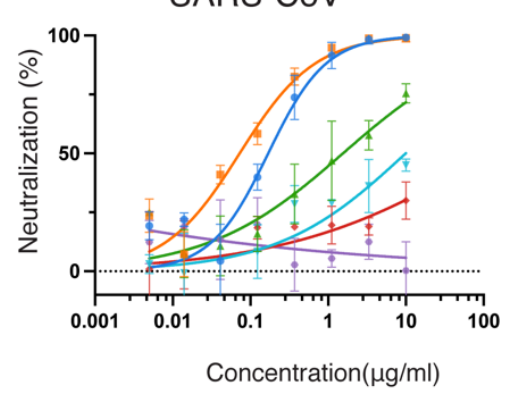

ADI-62104

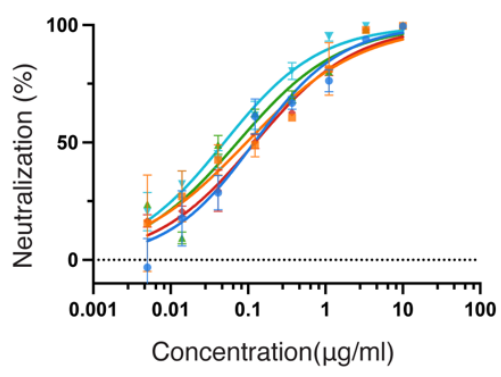

ADI-57843

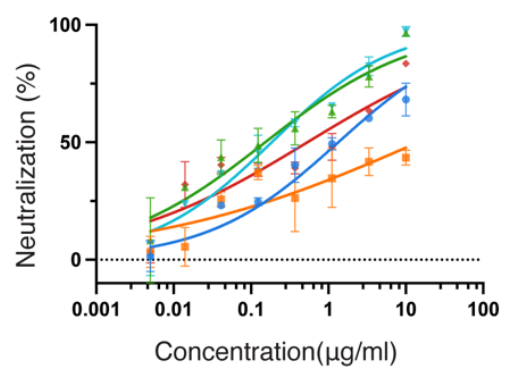

ADI-63219
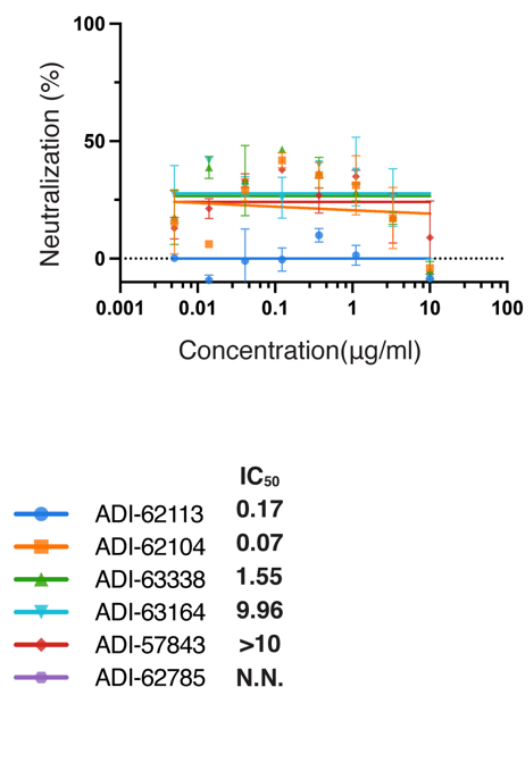

Figure S6. YYDRxG antibodies neutralize SARS-CoV-2 VOCs and SARS-CoV. ADI antibodies were tested in a neutralization assay against SARS-CoV-2 wild type (WT), VOCs, and SARS-

641 CoV pseudoviruses. Neutralization potencies, $I_{50} \mathrm{~S}$, are shown in Figure 5C. Consistent with the 
bioRxiv preprint doi: https://doi.org/10.1101/2021.12.15.472864; this version posted December 17,2021 . The copyright holder for this preprint (which was not certified by peer review) is the author/funder, who has granted bioRxiv a license to display the preprint in perpetuity. It is made available under aCC-BY-NC-ND 4.0 International license.

642 binding kinetics assay, most antibodies broadly neutralize SARS-CoV-2 variants (A) and SARS-

$643 \operatorname{CoV}(B)$. 


\section{SUPPLEMENTAL TABLE AND TABLE LEGENDS}

\section{Table S1. Crystallographic data collection and refinement statistics}

\begin{tabular}{|c|c|}
\hline \multicolumn{2}{|l|}{ Data collection } \\
\hline Beamline & SSRL 12-1 \\
\hline Wavelength $(\AA)$ & 0.97934 \\
\hline Space group & $P 4_{3} 2_{1} 2$ \\
\hline \multicolumn{2}{|l|}{ Unit cell parameters } \\
\hline$a, b, c(\AA)$ & $85.0,85.0,215.0$ \\
\hline$\alpha, \beta, \gamma\left({ }^{\circ}\right)$ & $90,90,90$ \\
\hline Resolution $(\AA ̊)$ a & $50.0-2.59$ (2.64-2.59) \\
\hline Unique reflections a & $25,315(1,241)$ \\
\hline Redundancy a & $6.7(5.8)$ \\
\hline Completeness (\%) a & $99.2(98.9)$ \\
\hline$<1 / \sigma_{1}>^{a}$ & $7.6(1.1)$ \\
\hline$R_{\mathrm{sym}}{ }^{\mathrm{b}}(\%)$ a & $23.7(>100)$ \\
\hline$R_{\text {pim }}$ b $(\%)$ a & $9.7(68.4)$ \\
\hline 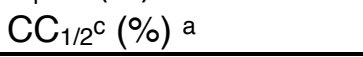 & $97.9(45.9)$ \\
\hline \multicolumn{2}{|c|}{ Refinement statistics } \\
\hline Resolution $(\AA)$ & $45.4-2.59$ \\
\hline Reflections (work) & 23,894 \\
\hline Reflections (test) & 1,170 \\
\hline$R_{\text {cryst }^{\mathrm{d}} / R_{\text {free }}}^{\mathrm{e}}(\%)$ & $22.1 / 26.7$ \\
\hline No. of atoms & 4,948 \\
\hline Macromolecules & 4,838 \\
\hline Glycans & 38 \\
\hline Solvent & 72 \\
\hline Average $B$-value $\left(\AA^{2}\right)$ & 42 \\
\hline Macromolecules & 42 \\
\hline Fab & 41 \\
\hline RBD & 45 \\
\hline Glycans & 77 \\
\hline Solvent & 40 \\
\hline Wilson $B$-value $\left(\AA^{2}\right)$ & 47 \\
\hline \multicolumn{2}{|c|}{ RMSD from ideal geometry } \\
\hline Bond length $(\AA)$ & 0.002 \\
\hline Bond angle (o) & 0.50 \\
\hline \multicolumn{2}{|c|}{ Ramachandran statistics (\%) } \\
\hline Favored & 96.5 \\
\hline Outliers & 0.0 \\
\hline PDB code & 7T7B \\
\hline
\end{tabular}

a Numbers in parentheses refer to the highest resolution shell.

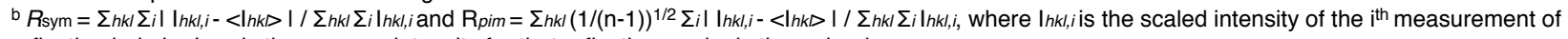
reflection $\mathrm{h}, \mathrm{k}, \mathrm{l},<\mathrm{l} h \mathrm{~h} \triangleright$ is the average intensity for that reflection, and $n$ is the redundancy.

${ }^{c} \mathrm{CC}_{1 / 2}=$ Pearson correlation coefficient between two random half datasets.

${ }^{d} R_{\text {cryst }}=\sum_{n k l}\left|F_{\mathrm{o}}-F_{\mathrm{c}}\right| / \sum_{n k l}\left|F_{\mathrm{o}}\right| \times 100$, where $F_{\mathrm{o}}$ and $F_{\mathrm{c}}$ are the observed and calculated structure factors, respectively.

e Riree was calculated as for Rcryst, but on a test set comprising $5 \%$ of the data excluded from refinement.

${ }^{\dagger}$ From MolProbity (Williams et al., 2018). 
bioRxiv preprint doi: https://doi.org/10.1101/2021.12.15.472864; this version posted December 17, 2021. The copyright holder for this preprint (which was not certified by peer review) is the author/funder, who has granted bioRxiv a license to display the preprint in perpetuity. It is made available under aCC-BY-NC-ND 4.0 International license.

Table S2. YYDRxG antibodies against SARS-CoV-2 with available neutralization data

\begin{tabular}{|c|c|c|c|c|c|c|c|c|c|c|c|}
\hline & Ab name & Neut. & Cr. & Epitope & CDR H3 & Len. & IGHV & IGHD & IGHJ & IGK/LV & PubMed ID \\
\hline 1 & ADI-62113 & Yes $^{*}$ & Yes $^{*}$ & RBD & ARAARPYYDRRGYFFRADYFQH & 22 & IGHV1-3 & IGHD3-22 & IGHJ1 & IGKV1-33 & 33622975 \\
\hline 2 & COVA1-16 & Yes & Yes & RBD & ARPPRNYYDRSGYYQRAEYFOH & 22 & IGHV1-46 & IGHD3-22 & IGHJ1 & IGKV1-33 & 32540902 \\
\hline 3 & $2-36$ & Yes & Yes & RBD & AREVYYYDRSGYYASDGFDI & 20 & IGHV4-61 & IGHD3-22 & IGHJ3 & IGKV3-20 & 34836485 \\
\hline 4 & ADI-63338 & Yes* $^{*}$ & Yes* $^{*}$ & RBD & ARLLIYYDRSGYYQQTDFDS & 20 & IGHV4-39 & IGHD3-22 & IGHJ4 & IGLV6-57 & 33622975 \\
\hline 5 & ADI-62104 & Yes* $^{*}$ & 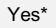 & RBD & ARDQYYYDRSGNYRGNGYFDY & 21 & IGHV1-69 & IGHD3-22 & IGHJ4 & IGKV1-33 & 33622975 \\
\hline 6 & C1463 & Yes & N.D. & RBD & ARQLYYYDRSGFLHGDAFDI & 20 & IGHV3-30-3 & IGHD3-22 & IGHJ3 & IGKV1-27 & 34619745 \\
\hline 7 & C996 & Yes & N.D. & RBD & ARGQRGYYDRSGYYWGWRAFDI & 22 & IGHV3-13 & IGHD3-22 & IGHJ3 & IGLV3-21 & 34126625 \\
\hline 8 & C634 & Yes & N.D. & RBD & ARSQYYYDRSGYANHDAFDI & 20 & IGHV3-33 & IGHD3-22 & IGHJ3 & IGKV1-5 & 33567448 \\
\hline 9 & C652 & Yes & N.D. & RBD & ARELYYYDRSGYYGPDDYAFDI & 22 & IGHV3-33 & IGHD3-22 & IGHJ3 & IGKV1-5 & 33567448 \\
\hline 10 & C868 & Yes & N.D. & RBD & ARETFFYDRTGHYKSDGFDV & 20 & IGHV4-61 & IGHD3-22 & IGHJ3 & IGKV1-5 & 34126625 \\
\hline 11 & C1381 & Yes & N.D. & RBD & ARGPRGYYDRTGHFYRNWYFEL & 22 & IGHV3-13 & IGHD3-22 & IGHJ2 & IGLV2-14 & 34619745 \\
\hline 12 & $\mathrm{C} 022$ & Yes & Yes & RBD & ARHAAAYYDRSGYYFIEYFQH & 21 & IGHV4-39 & IGHD3-22 & IGHJ1 & IGKV1-5 & 33948592 \\
\hline 13 & ADI-57843 & Yes $^{*}$ & Yes $^{*}$ & RBD & ARSTDYYDRSGHYRIDAFDI & 20 & IGHV2-26 & IGHD3-22 & IGHJ3 & IGKV3D-20 & 33622975 \\
\hline 14 & ADI-63164 & Yes $^{*}$ & Yes* $^{*}$ & RBD & ARQPREFYDRIGFYHVENYFEK & 22 & IGHV1-3 & IGHD3-22 & IGHJ4 & IGKV3-20 & 33622975 \\
\hline 15 & P008_076 & Yes & Yes & Spike & ARAHRGYYDRSGYYHNPDAFDI & 22 & IGHV3-13 & IGHD3-22 & IGHJ3 & IGLV2-14 & 33836142 \\
\hline 16 & ADI-62785 & Yes $^{*}$ & $\mathrm{No}^{*}$ & RBD & ARHGTPNYYDRSGNYNAGDWFDP & 23 & IGHV4-39 & IGHD3-22 & IGHJ5 & IGLV1-40 & 33622975 \\
\hline 17 & P054_003 & Yes & No & RBD & ARVARHYYDRSGNLHSADYFOH & 22 & IGHV1-2 & IGHD3-22 & IGHJ1 & IGKV1-33 & 33836142 \\
\hline 18 & MnC4t2p1_D10 & Yes & N.D. & RBD & ARGVNYYDRNGYYRNDGFDI & 20 & IGHV4-39 & IGHD3-22 & IGHJ3 & IGKV1-17 & 32673567 \\
\hline 19 & MnC4t1p1_A10 & Yes & N.D. & RBD & ARGVNYYDRNGYYRNDGFDI & 20 & IGHV4-39 & IGHD3-22 & IGHJ3 & IGKV1-17 & 32673567 \\
\hline 20 & MnC4t2p1_F5 & Yes & N.D. & RBD & ARGVNYYDRNGYYRNDGFDI & 20 & IGHV4-39 & IGHD3-22 & IGHJ3 & IGKV1-17 & 32673567 \\
\hline 21 & C1243 & Yes & N.D. & RBD & AKDGGPYYYDRSGYARDDYYGMDV & 24 & IGHV3-30 & IGHD3-22 & IGHJ6 & IGLV1-40 & 34619745 \\
\hline 22 & C1332 & Yes & N.D. & RBD & AKAPRGYYDRSGYYRIQDNFDY & 22 & IGHV3-30 & IGHD3-22 & IGHJ4 & IGKV1-13 & 34619745 \\
\hline 23 & ADI-63219 & $\mathrm{No}^{*}$ & & spike & ARAVILDYYDRGGFYGGETADVCDV & 25 & IGHV1-18 & IGHD3-22 & IGHJ6 & IGKV3-20 & 33622975 \\
\hline 24 & ADI-62969 & $\mathrm{No}^{*}$ & & spike & TPEGHYYYDRGGYOFGMDV & 19 & IGHV3-30 & IGHD3-22 & IGHJ6 & IGKV2-30 & 33622975 \\
\hline 25 & COVA2-47 & No & & Spike & AKVATYYYDRSGYYYGGALDY & 21 & IGHV3-9 & IGHD3-22 & IGHJ4 & IGKV4-1 & 32540902 \\
\hline 26 & P008_082 & No & & RBD & ARALENYYDRNGNYYVGAFDY & 21 & IGHV1-18 & IGHD3-22 & IGHJ4 & IGKV3-20 & 33836142 \\
\hline 27 & P008_093 & No & & RBD & ARSKERGYYNRTGYYYPGDWFDP & 23 & IGHV1-8 & IGHD3-22 & IGHJ5 & IGKV3-11 & 33836142 \\
\hline 28 & C83A5 & No & & RBD & ARDGAYYDRSAYYYRLKFYFDF & 22 & IGHV3-33 & IGHD3-22 & IGHJ4 & IGLV3-25 & 34332650 \\
\hline
\end{tabular}

654 Neut., neutralization against SARS-CoV-2; Cr., cross neutralization against both SARS-CoV-2

655 and SARS-CoV. Len., amino acid length of CDR H3 as defined by IMGT scheme. YYDRxG

656 antibodies tested against SARS-CoV-2 or SARS-CoV in previous publications or in this study

657 are included in this table. *neutralization data reported in this study. CDR H3 sequences, as well

658 as heavy variable (IGHV), diversity (IGHD), joining (IGHJ) genes, and light chain variable genes

659 (IGKV, IGLV) that encode these antibodies, are shown. 
bioRxiv preprint doi: https://doi.org/10.1101/2021.12.15.472864; this version posted December 17, 2021. The copyright holder for this preprint (which was not certified by peer review) is the author/funder, who has granted bioRxiv a license to display the preprint in perpetuity. It is made available under aCC-BY-NC-ND 4.0 International license.

Table S3. YYDRxG antibodies against SARS-CoV-2 with only sequences available

\begin{tabular}{|c|c|c|c|c|c|c|c|}
\hline & Ab name & $\mathrm{CDR} H 3$ & Len. & IGHV & IGHD & IHHJ & PubMed ID \\
\hline 1 & COV021_P1_IgA_48-P1609 & AKAALRGYYDRSGYYYENYNGMDV & 24 & IGHV3-30 & IGHD3-22 & IGHJ6 & 33288661 \\
\hline 2 & COVD21_P2_HC_H11-p1369 & ARHAAAYYDRSGYYF IEYFOH & 21 & IGHV4-39 & IGHD3-22 & IGHJ1 & 33288661 \\
\hline 3 & COV021_P3_IgA_29-P1609 & AKAALRGYYDRSGYYYENYNGMDV & 24 & IGHV3-30 & IGHD3-22 & IGHJ6 & 33288661 \\
\hline 4 & COVD21_P2_HC_H4-p1369 & ARQWRGYYDRSGYYHFDAFDI & 21 & IGHV5-51 & IGHD3-22 & IGHJ3 & 33288661 \\
\hline 5 & COVD21_P3_HC_C11-p1369 & ARVGYYYDRSGFPRTEDYFDY & 21 & IGHV1-69 & IGHD3-22 & IGHJ4 & 33288661 \\
\hline 6 & COV047_P5_IgG_15-P1369 & ARYTYYYDRSGYYRPDYFDY & 20 & IGHV1-69 & IGHD3-22 & IGHJ4 & 33288661 \\
\hline 7 & COV047_P3_IgG_77-P1369 & ARVPRGYYDRSGYYYLPHYLDY & 22 & IGHV1-18 & IGHD3-22 & IGHJ4 & 33288661 \\
\hline 8 & COV096_HC_72-p1369 & ARRPRDYYDRSGYYYVPGYFDY & 22 & IGHV1-18 & IGHD3-22 & IGHJ4 & 33288661 \\
\hline 9 & COV107_Plate2_HC_47-P1369 & TRGSRGYYDRSGYYTPLDPYYGMDV & 25 & IGHV3-21 & IGHD3-22 & IGHJ6 & 33288661 \\
\hline 10 & MOD3_P1_IgG_C3-P1369 & ARDRGYFNRTGNYYVGRFDP & 20 & IGHV3-33 & IGHD3-22 & IGHJ5 & 33567448 \\
\hline 11 & Mod4_P3_IgG_H4-P1369 & AKDWSAYYYDRSGYLRLDYYYGMDV & 25 & IGHV3-23 & IGHD3-22 & IGHJ6 & 33567448 \\
\hline 12 & Mod4_P3_IgG_H6-P1369 & ARPELGYFDRSGYYREGEFFDY & 22 & IGHV3-33 & IGHD3-22 & IGHJ4 & 33567448 \\
\hline 13 & Mod4_P4_IgG_G8-P1369 & ARTLYYYDRSGYGQSDDAFDI & 21 & IGHV3-74 & IGHD3-22 & IGHJ3 & 33567448 \\
\hline 14 & MOD8_P2_IgG_H4-P1369 & ARQEHYYDRSGYPRSDYAFEI & 21 & IGHV4-39 & IGHD3-22 & IGHJ3 & 33567448 \\
\hline 15 & MOD8_P2_IgG_G11-P1369 & ARSONYYDRSGSLAEDAFDI & 20 & IGHV3-33 & IGHD3-22 & IGHJ3 & 33567448 \\
\hline 16 & MOD8_P2_IgG_B11-P1369 & ARSQNYYDRSGYLAEDAFDI & 20 & IGHV3-33 & IGHD3-22 & IGHJ3 & 33567448 \\
\hline 17 & MOD8_P2_IgG_E11-P1369 & ARHEYYYDRRGYPRLGWFDP & 20 & IGHV4-39 & IGHD3-22 & IGHJ5 & 33567448 \\
\hline 18 & PZF12_P2_IgG_F7-P1369 & ARSPRGYYDRTGYYHLEYYFDY & 22 & IGHV3-30-3 & IGHD3-22 & IGHJ4 & 33567448 \\
\hline 19 & C001_P2_IgG_F6-P1369 & ARDPFYYDRSGSPRGDAFDI & 20 & IGHV3-33 & IGHD3-22 & IGHJ3 & 33567448 \\
\hline 20 & C003_P1_IgG_C3-P1369 & ARETWYYDRSGYPRSDEYFQY & 21 & IGHV1-69 & IGHD3-22 & IGHJ1 & 33567448 \\
\hline 21 & cov2-vax-3 & ARVVPNYFDRSGYYPGAFDI & 20 & IGHV3-21 & IGHD3-22 & IGHJ3 & 34411541 \\
\hline 22 & COVD21_mo6_HC_P2D12-p1369 & ARVPRDYYDRTGNHHVDEYFQH & 22 & IGHV3-74 & IGHD3-22 & IGHJ1 & 34126625 \\
\hline 23 & COVD21_mo6_HC_P1F9-p1369 & ARESFYYDRSGYYGSDAFDI & 20 & IGHV4-61 & IGHD3-22 & IGHJ3 & 34126625 \\
\hline 24 & COV21_1y_P1_IgG_A10-P1369 & ARETYYYDRSGYYSSDGFDY & 20 & IGHV4-61 & IGHD3-22 & IGHJ4 & 34126625 \\
\hline 25 & COV21_1y_P1_IgG_C1-P1369 & ARETFYYDRTGYYSSDGFDF & 20 & IGHV4-61 & IGHD3-22 & IGHJ4 & 34126625 \\
\hline 26 & COVD47_mo6_P1_HC_B1-p1369 & ATELYYYDRSGFQHWDGFAI & 20 & IGHV4-39 & IGHD3-22 & IGHJ3 & 34126625 \\
\hline 27 & COVD47_mo6_P1_HC_G7-p1369 & ARDMEVDYYDRSGHYHVFHAFDI & 23 & IGHV3-30 & IGHD3-22 & IGHJ3 & 34126625 \\
\hline 28 & COV47_1y_P2_IgG_B9-P1369 & ARRALGDYYDRTGYYHRLGFDS & 22 & IGHV5-51 & IGHD3-22 & IGHJ4 & 34126625 \\
\hline 29 & COV47_1y_P1_lgG_G5-P1369 & ARRALGDYYDRHGHFHRLGFDY & 22 & IGHV5-51 & IGHD3-22 & IGHJ4 & 34126625 \\
\hline 30 & COV47_1y_P2_IgG_D12-P1369 & ARHERSYYDRSGYYERRTLNDY & 22 & IGHV5-10-1 & IGHD3-22 & IGHJ4 & 34126625 \\
\hline 31 & COV47_1y_P2_IgG_B11-P1369 & AKEPRGYYDRSGDYYILPPDF & 21 & IGHV3-23 & IGHD3-22 & IGHJ4 & 34126625 \\
\hline 32 & COV57_1y_P2_lgG_A10-P1369 & ARGGRYYYDRSGYLKSDDVFDF & 22 & IGHV1-3 & IGHD3-22 & IGHJ3 & 34126625 \\
\hline 33 & COV57_1y_P2_IgG_E7-P1369 & ARGQRAYYNRTGHYWGWRALDI & 22 & IGHV3-13 & IGHD3-22 & IGHJ3 & 34126625 \\
\hline 34 & COV107_6mo_P1_IGG_F9-P1369 & ARPPRYYYDRSGYYVWEDYFDY & 22 & IGHV5-10-1 & IGHD3-22 & IGHJ4 & 34126625 \\
\hline 35 & COV107_6mo_P1_IGG_E11-P1369 & ARVPRGYYDRSGHYHGQDYFDY & 22 & IGHV1-3 & IGHD3-22 & IGHJ4 & 34126625 \\
\hline 36 & COV107_6mo_P1_IGG_B9-P1369 & ARLLHYYDRSGYSGATDDAFDI & 22 & IGHV5-51 & IGHD3-22 & IGHJ3 & 34126625 \\
\hline 37 & COV134_6mo_P1_IGG_B2-P1369 & ARHSAHYYDRSGKFHWGYLHR & 21 & IGHV4-39 & IGHD3-22 & IGHJ1 & 34126625 \\
\hline 38 & COV134_6mo_P1_IGG_B6-P1369 & ARTPDYYDRSGYLQTGSWFDP & 21 & IGHV1-18 & IGHD3-22 & IGHJ5 & 34126625 \\
\hline 39 & COV134_6mo_P1_IGG_H8-P1369 & ARDLYYYDRSGNYNLEEYFQQ & 21 & IGHV1-69 & IGHD3-22 & IGHJ1 & 34126625 \\
\hline 40 & COV134_6mo_P1_IGG_D5-P1369 & ARGSANYYDRHGHYYVASFLAN & 22 & IGHV1-69 & IGHD3-22 & IGHJ4 & 34126625 \\
\hline 41 & COV135_6m_P2_IgG_D9-P1369 & ARDVYYYDRSGYLRFDFDN & 19 & IGHV4-39 & IGHD3-22 & IGHJ4 & 34126625 \\
\hline 42 & COV135_1y_P2_IgG_E9-P1369 & ARPPRDYYERSGYYRFADYFQH & 22 & IGHV3-7 & IGHD3-22 & IGHJ1 & 34126625 \\
\hline 43 & COV135_1y_P2_lgG_F2-P1369 & AKVSSPNYYDRSGKVRSEREDAFDI & 25 & IGHV3-23 & IGHD3-22 & IGHJ3 & 34126625 \\
\hline 44 & COV325_1m_P3_IgG_C3-P1369 & TRDLRAYYDRSGYYVYGIGTDY & 22 & IGHV1-46 & IGHD3-22 & IGHJ4 & 34126625 \\
\hline 45 & COV325_6m_P2_IgG_H9-P1369 & ARASGINYYDRSGNYNVDYYHYGMDV & 26 & IGHV3-33 & IGHD3-22 & IGHJ6 & 34126625 \\
\hline 46 & COV325_1y_P1_IgG_E7-P1369 & AREVYYYDRRGYYKSEGFDH & 20 & IGHV4-61 & IGHD3-22 & IGHJ4 & 34126625 \\
\hline 47 & COV325_6m_P1_lgG_C11-P1369 & ARDHIASYYDRSGHYHYYGMDV & 22 & IGHV1-69 & IGHD3-22 & IGHJ6 & 34126625 \\
\hline 48 & COV539_1m_P3_lgG_F12-P1369 & ARRPRGYYDRSGYYILEDYFEY & 22 & IGHV3-33 & IGHD3-22 & IGHJ4 & 34126625 \\
\hline 49 & Cov539_1m_P2_lgG_C7-P1369 & ARHEYYYDRRGYSRLGWFDP & 20 & IGHV4-39 & IGHD3-22 & IGHJ5 & 34126625 \\
\hline 50 & COV539_6m_P2_IgG_C10-P1369 & ARRPRGYYDRSGFYNVEDYFDY & 22 & IGHV3-33 & IGHD3-22 & IGHJ4 & 34126625 \\
\hline 51 & C006_mo6_HC_P4D5-1369 & ARAGRDYYDRSGYHGHDAFDI & 21 & IGHV3-53 & IGHD3-22 & IGHJ3 & 34619745 \\
\hline 52 & C012_V1_P1_IgG_E1-P1369 & ARSPRGYYDRSGYLNLLWYFDY & 22 & IGHV3-33 & IGHD3-22 & IGHJ4 & 34619745 \\
\hline 53 & C012_VAX2_HC_P1C11-1369 & AREPRDYYDRSGYHRFLHYFEY & 22 & IGHV3-48 & IGHD3-22 & IGHJ4 & 34619745 \\
\hline 54 & C012_mo6_HC_P4A3-1369 & ARRPRGYYDRSGYYHSIGYMDV & 22 & IGHV3-30 & IGHD3-22 & IGHJ6 & 34619745 \\
\hline 55 & C012_mo6_HC_P3H8-1369 & ARRPRGYYDRSGYYHSIGYMDV & 22 & IGHV3-30 & IGHD3-22 & IGHJ6 & 34619745 \\
\hline 56 & C012_mo6_HC_P3E12-1369 & ARRPRGYYDRSGYYHSIGYMDV & 22 & IGHV3-30 & IGHD3-22 & IGHJ6 & 34619745 \\
\hline 57 & C012_mo6_HC_P3G1-1369 & ARRPRGYYDRSGYYHSIGYMDV & 22 & IGHV3-30 & IGHD3-22 & IGHJ6 & 34619745 \\
\hline 58 & C012_mo6_HC_P1E5-1369 & ARRPRGYYDRSGYYHSIGYMDV & 22 & IGHV3-30 & IGHD3-22 & IGHJ6 & 34619745 \\
\hline 59 & C012_mo6_HC_P1E7-1369 & ARVNYYYDRSGQPTLDDIFNI & 21 & IGHV1-69 & IGHD3-22 & IGHJ3 & 34619745 \\
\hline 60 & C012_mo6_HC_P2B2-1369 & ARFGAYYDRTGYKKFEYFOH & 20 & IGHV5-51 & IGHD3-22 & IGHJ1 & 34619745 \\
\hline 61 & C016_mo6_HC_P2F10-1369 & ARRPRGYYDRSGYYHSIGYMDV & 22 & IGHV3-30 & IGHD3-22 & IGHJ6 & 34619745 \\
\hline 62 & C016_mo6_HC_P1B9-1369 & ARRPRGYYDRSGYYHSIGYMDV & 22 & IGHV3-30 & IGHD3-22 & IGHJ6 & 34619745 \\
\hline 63 & C016_mo6_HC_P1C2-1369 & ARALCYYDRSGNYLTEDYFDH & 21 & IGHV1-3 & IGHD3-22 & IGHJ4 & 34619745 \\
\hline 64 & C017_Vax2_HC_P2H8-1369 & ASCRYYYDRSGYAQPEDYFDY & 21 & IGHV1-69 & IGHD3-22 & IGHJ4 & 34619745 \\
\hline 65 & C003_6m_P1_lgG_H7-P1369 & AKVGYYFDRNGSPRDENYYYYGMDV & 25 & IGHV3-30 & IGHD3-22 & IGHJ6 & 34619745 \\
\hline 66 & C003_6m_P3_lgG_H6-P1369 & ARDVPLYYDRSGNYGLAEYFQY & 22 & IGHV1-18 & IGHD3-22 & IGHJ1 & 34619745 \\
\hline 67 & C003_6m_P3_IgG_C12-P1369 & ARSPRDYYDRRGQIVVERWFDP & 22 & IGHV4-59 & IGHD3-22 & IGHJ5 & 34619745 \\
\hline 68 & C003_mo6_HC_P7A9-1369 & ARRPRGYYDRSGYYHSIGYMDV & 22 & IGHV3-30 & IGHD3-22 & IGHJ6 & 34619745 \\
\hline 69 & C004_mo6_HC_P4E5-1369 & ARAGRDYYDRSGYHGHDAFDI & 21 & IGHV3-53 & IGHD3-22 & IGHJ3 & 34619745 \\
\hline 70 & C004_mo6_HC_P4A3-1369 & ARRPRGYYDRSGYYHSIGYMDV & 22 & IGHV3-30 & IGHD3-22 & IGHJ6 & 34619745 \\
\hline 71 & C004_mo6_HC_P3F4-1369 & ARRPRGYYDRSGYYHSIGYMDV & 22 & IGHV3-30 & IGHD3-22 & IGHJ6 & 34619745 \\
\hline 72 & C004_mo6_HC_P4F5-1369 & ARRPRGYYDRSGYYHSIGYMDV & 22 & IGHV3-30 & IGHD3-22 & IGHJ6 & 34619745 \\
\hline
\end{tabular}

661 YYDRxG antibodies against SARS-CoV-2 with no available antigen binding or neutralization 662 data are included in this table. CDR H3 sequences, as well as heavy variable (IGHV), diversity 663 (IGHD), and joining (IGHJ) genes that encode these antibodies, are shown. 
Table S4. YYDRXG antibodies sequenced from COVID-19 patients and vaccinees

\begin{tabular}{c|lccl}
\multicolumn{1}{c}{ ID } & $\begin{array}{c}\text { Patient } \\
\text { analyzed }\end{array}$ & $\begin{array}{c}\text { YYDRxG } \\
\text { found }\end{array}$ & $\begin{array}{c}\text { Patient } \\
\text { group }\end{array}$ \\
\hline 1 & COV021 & 1689 & 11 & Infection \\
2 & COV047 & 1346 & 8 & Infection \\
3 & COV072 & 1031 & 0 & Infection \\
4 & COV107 & 1376 & 4 & Infection \\
5 & COV057 & 739 & 3 & Infection+vaccination \\
6 & COV096 & 1331 & 1 & Infection+vaccination \\
7 & COV134 & 515 & 4 & Infection+vaccination \\
8 & COV135 & 531 & 3 & Infection+vaccination \\
9 & COV325 & 708 & 4 & Infection+vaccination \\
10 & COV539 & 778 & 3 & Infection+vaccination \\
11 & C001 & 556 & 1 & Vaccination \\
12 & C003 & 536 & 6 & Vaccination \\
13 & C004 & 592 & 5 & Vaccination \\
14 & C005 & 215 & 1 & Vaccination \\
15 & C006 & 326 & 1 & Vaccination \\
16 & C011 & 526 & 0 & Vaccination \\
17 & C012 & 683 & 9 & Vaccination \\
18 & C016 & 742 & 3 & Vaccination \\
19 & C017 & 421 & 1 & Vaccination \\
20 & C030 & 224 & 1 & Vaccination \\
21 & C034 & 343 & 0 & Vaccination \\
22 & MOD1 & 136 & 0 & Vaccination \\
23 & MOD11 & 218 & 0 & Vaccination \\
24 & MOD2 & 89 & 1 & Vaccination \\
25 & MOD3 & 233 & 2 & Vaccination \\
26 & MOD4 & 245 & 3 & Vaccination \\
27 & MOD6 & 220 & 0 & Vaccination \\
28 & MOD7 & 218 & 0 & Vaccination \\
29 & MOD8 & 288 & 4 & Vaccination \\
30 & MOD9 & 203 & 0 & Vaccination \\
31 & PZF10 & 263 & 0 & Vaccination \\
32 & PZF12 & 180 & 1 & Vaccination \\
& & & &
\end{tabular}

665 A YYDRxG pattern search was used to identify antibody sequences in previously reported cohorts 666 (Cho et al., 2021; Gaebler et al., 2021; Robbiani et al., 2020; Z. Wang, J. C. C. Lorenzi, et al., 667 2021; Z. Wang, F. Muecksch, et al., 2021; Z. Wang, F. Schmidt, et al., 2021). Number of all 668 antibody sequences analyzed and YYDRxG antibodies identified in each patient was counted and 669 used for analysis in Figure 6B. 


\section{REFERENCES}

671

672

673

674

675

676

677

678

679

680

681

682

683

684

685

686

687

688

689

690

691

692

Adams, P. D., Afonine, P. V., Bunkoczi, G., Chen, V. B., Davis, I. W., Echols, N., Headd, J. J., Hung, L.-W., Kapral, G. J., Grosse-Kunstleve, R. W., McCoy, A. J., Moriarty, N. W., Oeffner, R., Read, R. J., Richardson, D. C., Richardson, J. S., Terwilliger, T. C., \& Zwart, P. H. (2010). PHENIX: a comprehensive Python-based system for macromolecular structure solution. Acta Crystallographica Section D-Biological Crystallography, 66(2), 213-221. https://doi.org/doi:10.1107/S0907444909052925

Andrabi, R., Voss, J. E., Liang, C. H., Briney, B., McCoy, L. E., Wu, C. Y., Wong, C. H., Poignard, P., \& Burton, D. R. (2015, Nov 17). Identification of common features in prototype broadly neutralizing antibodies to HIV envelope V2 apex to facilitate vaccine design. Immunity, 43(5), 959-973. https://doi.org/10.1016/j.immuni.2015.10.014

Andreano, E., Nicastri, E., Paciello, I., Pileri, P., Manganaro, N., Piccini, G., Manenti, A., Pantano, E., Kabanova, A., Troisi, M., Vacca, F., Cardamone, D., De Santi, C., Torres, J. L., Ozorowski, G., Benincasa, L., Jang, H., Di Genova, C., Depau, L., Brunetti, J., Agrati, C., Capobianchi, M. R., Castilletti, C., Emiliozzi, A., Fabbiani, M., Montagnani, F., Bracci, L., Sautto, G., Ross, T. M., Montomoli, E., Temperton, N., Ward, A. B., Sala, C., Ippolito, G., \& Rappuoli, R. (2021, Apr 1). Extremely potent human monoclonal antibodies from COVID-19 convalescent patients. Cell, 184(7), 1821-1835.e1816. https://doi.org/10.1016/j.cell.2021.02.035

Ashkenazy, H., Abadi, S., Martz, E., Chay, O., Mayrose, I., Pupko, T., \& Ben-Tal, N. (2016, Jul 8). ConSurf 2016: an improved methodology to estimate and visualize evolutionary conservation in macromolecules. Nucleic Acids Res, 44(W1), W344-350. https://doi.org/10.1093/nar/gkw408

Briney, B., Inderbitzin, A., Joyce, C., \& Burton, D. R. (2019, Feb). Commonality despite exceptional diversity in the baseline human antibody repertoire. Nature, 566(7744), 393397. https://doi.org/10.1038/s41586-019-0879-y

Brouwer, P. J. M., Caniels, T. G., van der Straten, K., Snitselaar, J. L., Aldon, Y., Bangaru, S., Torres, J. L., Okba, N. M. A., Claireaux, M., Kerster, G., Bentlage, A. E. H., van Haaren, M. M., Guerra, D., Burger, J. A., Schermer, E. E., Verheul, K. D., van der Velde, N., van der Kooi, A., van Schooten, J., van Breemen, M. J., Bijl, T. P. L., Sliepen, K., Aartse, A., Derking, R., Bontjer, I., Kootstra, N. A., Wiersinga, W. J., Vidarsson, G., Haagmans, B. L., Ward, A. B., de Bree, G. J., Sanders, R. W., \& van Gils, M. J. (2020, Aug 7). Potent neutralizing antibodies from COVID-19 patients define multiple targets of vulnerability. Science, 369(6504), 643-650. https://doi.org/10.1126/science.abc5902

Cao, Y., Su, B., Guo, X., Sun, W., Deng, Y., Bao, L., Zhu, Q., Zhang, X., Zheng, Y., Geng, C., Chai, X., He, R., Li, X., Lv, Q., Zhu, H., Deng, W., Xu, Y., Wang, Y., Qiao, L., Tan, Y., Song, 
L., Wang, G., Du, X., Gao, N., Liu, J., Xiao, J., Su, X. D., Du, Z., Feng, Y., Qin, C., Qin, C., Jin, R., \& Xie, X. S. (2020, Jul 9). Potent neutralizing antibodies against SARS-CoV-2 identified by high-throughput single-cell sequencing of convalescent patients' B cells. Cell, 182(1), 73-84.e16. https://doi.org/10.1016/j.cell.2020.05.025

Chan, A. W., Hutchinson, E. G., Harris, D., \& Thornton, J. M. (1993, Oct). Identification, classification, and analysis of beta-bulges in proteins. Protein Science, 2(10), 1574-1590. https://doi.org/10.1002/pro.5560021004

Chen, E. C., Gilchuk, P., Zost, S. J., Suryadevara, N., Winkler, E. S., Cabel, C. R., Binshtein, E., Chen, R. E., Sutton, R. E., Rodriguez, J., Day, S., Myers, L., Trivette, A., Williams, J. K., Davidson, E., Li, S., Doranz, B. J., Campos, S. K., Carnahan, R. H., Thorne, C. A., Diamond, M. S., \& Crowe, J. E., Jr. (2021, Aug 24). Convergent antibody responses to the SARS-CoV-2 spike protein in convalescent and vaccinated individuals. Cell Reports, 36(8), 109604. https://doi.org/10.1016/j.celrep.2021.109604

Chen, R. E., Zhang, X., Case, J. B., Winkler, E. S., Liu, Y., VanBlargan, L. A., Liu, J., Errico, J. M., Xie, X., Suryadevara, N., Gilchuk, P., Zost, S. J., Tahan, S., Droit, L., Turner, J. S., Kim, W., Schmitz, A. J., Thapa, M., Wang, D., Boon, A. C. M., Presti, R. M., O'Halloran, J. A., Kim, A. H. J., Deepak, P., Pinto, D., Fremont, D. H., Crowe, J. E., Jr., Corti, D., Virgin, H. W., Ellebedy, A. H., Shi, P. Y., \& Diamond, M. S. (2021, Apr). Resistance of SARS-CoV-2 variants to neutralization by monoclonal and serum-derived polyclonal antibodies. Nat Med, 27(4), 717-726. https://doi.org/10.1038/s41591-021-01294-w

Cho, A., Muecksch, F., Schaefer-Babajew, D., Wang, Z., Finkin, S., Gaebler, C., Ramos, V., Cipolla, M., Mendoza, P., Agudelo, M., Bednarski, E., DaSilva, J., Shimeliovich, I., Dizon, J., Daga, M., Millard, K. G., Turroja, M., Schmidt, F., Zhang, F., Tanfous, T. B., Jankovic, M., Oliveria, T. Y., Gazumyan, A., Caskey, M., Bieniasz, P. D., Hatziioannou, T., \& Nussenzweig, M. C. (2021, Oct 7). Anti-SARS-CoV-2 receptor-binding domain antibody evolution after mRNA vaccination. Nature. https://doi.org/10.1038/s41586-021-04060-7

Cock, P. J., Antao, T., Chang, J. T., Chapman, B. A., Cox, C. J., Dalke, A., Friedberg, I., Hamelryck, T., Kauff, F., Wilczynski, B., \& de Hoon, M. J. (2009, Jun 1). Biopython: freely available Python tools for computational molecular biology and bioinformatics. Bioinformatics, 25(11), 1422-1423. https://doi.org/10.1093/bioinformatics/btp163

Craveur, P., Joseph, A. P., Rebehmed, J., \& de Brevern, A. G. (2013, Oct). $\beta$-Bulges: extensive structural analyses of $\beta$-sheets irregularities. Protein Science, 22(10), 1366-1378. https://doi.org/10.1002/pro.2324 
Di Noia, J. M., \& Neuberger, M. S. (2007). Molecular mechanisms of antibody somatic hypermutation. Annu Rev Biochem, 76, 1-22.

https://doi.org/10.1146/annurev.biochem.76.061705.090740

Edgar, R. C. (2004). MUSCLE: multiple sequence alignment with high accuracy and high throughput. Nucleic Acids Res, 32(5), 1792-1797. https://doi.org/10.1093/nar/gkh340

Ekiert, D. C., Friesen, R. H., Bhabha, G., Kwaks, T., Jongeneelen, M., Yu, W., Ophorst, C., Cox,

Franklin, A., \& Blanden, R. V. (2006, May). A/T-targeted somatic hypermutation: critique of the mainstream model. Trends Biochem Sci, 31(5), 252-258. https://doi.org/10.1016/j.tibs.2006.03.008

Gaebler, C., Wang, Z., Lorenzi, J. C. C., Muecksch, F., Finkin, S., Tokuyama, M., Cho, A., Jankovic, M., Schaefer-Babajew, D., Oliveira, T. Y., Cipolla, M., Viant, C., Barnes, C. O., Bram, Y., Breton, G., Hagglof, T., Mendoza, P., Hurley, A., Turroja, M., Gordon, K., Millard, K. G., Ramos, V., Schmidt, F., Weisblum, Y., Jha, D., Tankelevich, M., Martinez-Delgado, G., Yee, J., Patel, R., Dizon, J., Unson-O'Brien, C., Shimeliovich, I., Robbiani, D. F., Zhao, Z., Gazumyan, A., Schwartz, R. E., Hatziioannou, T., Bjorkman, P. J., Mehandru, S., Bieniasz, P. D., Caskey, M., \& Nussenzweig, M. C. (2021, Mar). Evolution of antibody immunity to SARS-CoV-2. Nature, 591(7851), 639-644. https://doi.org/10.1038/s41586-021$\underline{03207-w}$

Giudicelli, V., \& Lefranc, M. P. (2011, Jun 1). IMGT/junctionanalysis: IMGT standardized analysis of the V-J and V-D-J junctions of the rearranged immunoglobulins (IG) and T cell receptors (TR). Cold Spring Harb Protoc, 2011(6), 716-725. https://doi.org/10.1101/pdb.prot5634

Gorman, J., Soto, C., Yang, M. M., Davenport, T. M., Guttman, M., Bailer, R. T., Chambers, M., Chuang, G. Y., DeKosky, B. J., Doria-Rose, N. A., Druz, A., Ernandes, M. J., Georgiev, I. S., Jarosinski, M. C., Joyce, M. G., Lemmin, T. M., Leung, S., Louder, M. K., McDaniel, J. R., Narpala, S., Pancera, M., Stuckey, J., Wu, X., Yang, Y., Zhang, B., Zhou, T., Program, N. C. S., Mullikin, J. C., Baxa, U., Georgiou, G., McDermott, A. B., Bonsignori, M., Haynes, B. F., Moore, P. L., Morris, L., Lee, K. K., Shapiro, L., Mascola, J. R., \& Kwong, P. D. (2016, 
Graham, C., Seow, J., Huettner, I., Khan, H., Kouphou, N., Acors, S., Winstone, H., Pickering, S., Galao, R. P., Dupont, L., Lista, M. J., Jimenez-Guardeno, J. M., Laing, A. G., Wu, Y., Joseph, M., Muir, L., van Gils, M. J., Ng, W. M., Duyvesteyn, H. M. E., Zhao, Y., Bowden, T. A., Shankar-Hari, M., Rosa, A., Cherepanov, P., McCoy, L. E., Hayday, A. C., Neil, S. J. D., Malim, M. H., \& Doores, K. J. (2021, Jun 8). Neutralization potency of monoclonal antibodies recognizing dominant and subdominant epitopes on SARS-CoV-2 Spike is impacted by the B.1.1.7 variant. Immunity, 54(6), 1276-1289.e1276. https://doi.org/10.1016/j.immuni.2021.03.023

Greaney, A. J., Loes, A. N., Gentles, L. E., Crawford, K. H. D., Starr, T. N., Malone, K. D., Chu, H. Y., \& Bloom, J. D. (2021, Jun 30). Antibodies elicited by mRNA-1273 vaccination bind more broadly to the receptor binding domain than do those from SARS-CoV-2 infection. Science Translational Medicine, 13(600), eabi9915. https://doi.org/10.1126/scitranslmed.abi9915

He, W.-t., Musharrafieh, R., Song, G., Dueker, K., Callaghan, S., Yong, P., Beutler, N., Torres, J. L., Volk, R. M., Zhou, P., Yuan, M., Liu, H., Anzanello, F., Parren, M., Garcia, E., Rawlings, S. A., Smith, D. M., Wilson, I. A., Ward, A. B., Rogers, T. F., Burton, D. R., \& Andrabi, R. (2021). Targeted isolation of panels of diverse human broadly neutralizing antibodies against SARS-like viruses. bioRxiv. https://doi.org/10.1101/2021.09.08.459480

Hoffmann, M., Arora, P., Gross, R., Seidel, A., Hornich, B. F., Hahn, A. S., Kruger, N., Graichen, L., Hofmann-Winkler, H., Kempf, A., Winkler, M. S., Schulz, S., Jack, H. M., Jahrsdorfer, B., Schrezenmeier, H., Muller, M., Kleger, A., Munch, J., \& Pohlmann, S. (2021, Apr 29). SARS-CoV-2 variants B.1.351 and P.1 escape from neutralizing antibodies. Cell, 184(9), 2384-2393.e2312. https://doi.org/10.1016/j.cell.2021.03.036

Jalkanen, P., Kolehmainen, P., Hakkinen, H. K., Huttunen, M., Tahtinen, P. A., Lundberg, R., Maljanen, S., Reinholm, A., Tauriainen, S., Pakkanen, S. H., Levonen, I., Nousiainen, A., Miller, T., Valimaa, H., Ivaska, L., Pasternack, A., Naves, R., Ritvos, O., Osterlund, P., Kuivanen, S., Smura, T., Hepojoki, J., Vapalahti, O., Lempainen, J., Kakkola, L., Kantele, A., \& Julkunen, I. (2021, Jun 28). COVID-19 mRNA vaccine induced antibody responses against three SARS-CoV-2 variants. Nature Communications, 12(1), 3991. https://doi.org/10.1038/s41467-021-24285-4

Jette, C. A., Cohen, A. A., Gnanapragasam, P. N. P., Muecksch, F., Lee, Y. E., Huey-Tubman, K. E., Schmidt, F., Hatziioannou, T., Bieniasz, P. D., Nussenzweig, M. C., West, A. P., Jr., Keeffe, J. R., Bjorkman, P. J., \& Barnes, C. O. (2021, Sep 28). Broad cross-reactivity 
across sarbecoviruses exhibited by a subset of COVID-19 donor-derived neutralizing antibodies. Cell Reports, 36(13), 109760. https://doi.org/10.1016/j.celrep.2021.109760

Jiang, W., Wang, J., Jiao, S., Gu, C., Xu, W., Chen, B., Wang, R., Chen, H., Xie, Y., Wang, A., Li, G., Zeng, D., Zhang, J., Zhang, M., Wang, S., Wang, M., \& Gui, X. (2021, Jan-Dec). Characterization of MW06, a human monoclonal antibody with cross-neutralization activity against both SARS-CoV-2 and SARS-CoV. MAbs, 13(1), 1953683. https://doi.org/10.1080/19420862.2021.1953683

Kreer, C., Zehner, M., Weber, T., Ercanoglu, M. S., Gieselmann, L., Rohde, C., Halwe, S., Korenkov, M., Schommers, P., Vanshylla, K., Di Cristanziano, V., Janicki, H., Brinker, R., Ashurov, A., Krahling, V., Kupke, A., Cohen-Dvashi, H., Koch, M., Eckert, J. M., Lederer, S., Pfeifer, N., Wolf, T., Vehreschild, M., Wendtner, C., Diskin, R., Gruell, H., Becker, S., \& Klein, F. (2020, Aug 20). Longitudinal isolation of potent near-germline SARS-CoV-2neutralizing antibodies from COVID-19 patients. Cell, 182(4), 843-854.e812. https://doi.org/10.1016/j.cell.2020.06.044

Kreye, J., Reincke, S. M., Kornau, H. C., Sanchez-Sendin, E., Corman, V. M., Liu, H., Yuan, M., Wu, N. C., Zhu, X., Lee, C. D., Trimpert, J., Holtje, M., Dietert, K., Stoffler, L., von Wardenburg, N., van Hoof, S., Homeyer, M. A., Hoffmann, J., Abdelgawad, A., Gruber, A. D., Bertzbach, L. D., Vladimirova, D., Li, L. Y., Barthel, P. C., Skriner, K., Hocke, A. C., Hippenstiel, S., Witzenrath, M., Suttorp, N., Kurth, F., Franke, C., Endres, M., Schmitz, D., Jeworowski, L. M., Richter, A., Schmidt, M. L., Schwarz, T., Muller, M. A., Drosten, C., Wendisch, D., Sander, L. E., Osterrieder, N., Wilson, I. A., \& Pruss, H. (2020, Nov 12). A therapeutic non-self-reactive SARS-CoV-2 antibody protects from lung pathology in a COVID-19 hamster model. Cell, 183(4), 1058-1069.e1019.

https://doi.org/10.1016/j.cell.2020.09.049

Krissinel, E., \& Henrick, K. (2007, Sep 21). Inference of macromolecular assemblies from crystalline state. Journal of Molecular Biology, 372(3), 774-397. https://doi.org/10.1016/j.jmb.2007.05.022

Landau, M., Mayrose, I., Rosenberg, Y., Glaser, F., Martz, E., Pupko, T., \& Ben-Tal, N. (2005, Jul 1). ConSurf 2005: the projection of evolutionary conservation scores of residues on protein structures. Nucleic Acids Res, 33(Web Server issue), W299-302. https://doi.org/10.1093/nar/gki370

Li, D., Edwards, R. J., Manne, K., Martinez, D. R., Schafer, A., Alam, S. M., Wiehe, K., Lu, X., Parks, R., Sutherland, L. L., Oguin, T. H., 3rd, McDanal, C., Perez, L. G., Mansouri, K., Gobeil, S. M. C., Janowska, K., Stalls, V., Kopp, M., Cai, F., Lee, E., Foulger, A., Hernandez, G. E., Sanzone, A., Tilahun, K., Jiang, C., Tse, L. V., Bock, K. W., Minai, M., Nagata, B. M., Cronin, K., Gee-Lai, V., Deyton, M., Barr, M., Von Holle, T., Macintyre, A. N., Stover, E., Feldman, J., Hauser, B. M., Caradonna, T. M., Scobey, T. D., Rountree, W., 
Wang, Y., Moody, M. A., Cain, D. W., DeMarco, C. T., Denny, T. N., Woods, C. W., Petzold, E. W., Schmidt, A. G., Teng, I. T., Zhou, T., Kwong, P. D., Mascola, J. R., Graham, B. S., Moore, I. N., Seder, R., Andersen, H., Lewis, M. G., Montefiori, D. C., Sempowski, G. D., Baric, R. S., Acharya, P., Haynes, B. F., \& Saunders, K. O. (2021, Aug 5). In vitro and in vivo functions of SARS-CoV-2 infection-enhancing and neutralizing antibodies. Cell, 184(16), 4203-4219.e4232. https://doi.org/10.1016/j.cell.2021.06.021

Liu, H., Wu, N. C., Yuan, M., Bangaru, S., Torres, J. L., Caniels, T. G., van Schooten, J., Zhu, X., Lee, C. D., Brouwer, P. J. M., van Gils, M. J., Sanders, R. W., Ward, A. B., \& Wilson, I. A. (2020, Dec 15). Cross-neutralization of a SARS-CoV-2 antibody to a functionally conserved site is mediated by avidity. Immunity, 53(6), 1272-1280.e1275. https://doi.org/10.1016/j.immuni.2020.10.023

Liu, H., Yuan, M., Huang, D., Bangaru, S., Zhao, F., Lee, C. D., Peng, L., Barman, S., Zhu, X., Nemazee, D., Burton, D. R., van Gils, M. J., Sanders, R. W., Kornau, H. C., Reincke, S. M., Pruss, H., Kreye, J., Wu, N. C., Ward, A. B., \& Wilson, I. A. (2021, May 12). A combination of cross-neutralizing antibodies synergizes to prevent SARS-CoV-2 and SARS-CoV pseudovirus infection. Cell Host \& Microbe, 29(5), 806-818.e806. https://doi.org/10.1016/j.chom.2021.04.005

Liu, J., Liu, Y., Xia, H., Zou, J., Weaver, S. C., Swanson, K. A., Cai, H., Cutler, M., Cooper, D., Muik, A., Jansen, K. U., Sahin, U., Xie, X., Dormitzer, P. R., \& Shi, P. Y. (2021, Aug). BNT162b2-elicited neutralization of B.1.617 and other SARS-CoV-2 variants. Nature, 596(7871), 273-275. https://doi.org/10.1038/s41586-021-03693-y

Madeira, F., Park, Y. M., Lee, J., Buso, N., Gur, T., Madhusoodanan, N., Basutkar, P., Tivey, A. R. N., Potter, S. C., Finn, R. D., \& Lopez, R. (2019, Jul 2). The EMBL-EBI search and sequence analysis tools APIs in 2019. Nucleic Acids Res, 47(W1), W636-W641. https://doi.org/10.1093/nar/gkz268

920

Martinez, D. R., Schafer, A., Gobeil, S., Li, D., De la Cruz, G., Parks, R., Lu, X., Barr, M., Stalls, V., Janowska, K., Beaudoin, E., Manne, K., Mansouri, K., Edwards, R. J., Cronin, K., Yount, B., Anasti, K., Montgomery, S. A., Tang, J., Golding, H., Shen, S., Zhou, T., Kwong, P. D., Graham, B. S., Mascola, J. R., Montefiori, D. C., Alam, S. M., Sempowski, G. D., Khurana, S., Wiehe, K., Saunders, K. O., Acharya, P., Haynes, B. F., \& Baric, R. S. (2021, Nov 2). A broadly cross-reactive antibody neutralizes and protects against sarbecovirus challenge in mice. Science Translational Medicine. https://doi.org/10.1126/scitranslmed.abj7125

McCoy, A. J., Grosse-Kunstleve, R. W., Adams, P. D., Winn, M. D., Storoni, L. C., \& Read, R. J. (2007, Aug 1). Phaser crystallographic software [Article]. J Appl Crystallogr, 40(Pt 4), 658674. https://doi.org/10.1107/S0021889807021206 
Otwinowski, Z., \& Minor, W. (1997). Processing of X-ray diffraction data collected in oscillation mode. Methods Enzymol, 276, 307-326. https://www.ncbi.nlm.nih.gov/pubmed/27754618

Pegu, A., O'Connell, S., Schmidt, S. D., O'Dell, S., Talana, C. A., Lai, L., Albert, J., Anderson, E., Bennett, H., Corbett, K. S., Flach, B., Jackson, L., Leav, B., Ledgerwood, J. E., Luke, C. J., Makowski, M., Roberts, P. C., Roederer, M., Rebolledo, P. A., Rostad, C. A., Rouphael, N. G., Shi, W., Wang, L., Widge, A. T., Yang, E. S., m, R. N. A. S. G., Beigel, J. H., Graham, B. S., Mascola, J. R., Suthar, M. S., McDermott, A., \& Doria-Rose, N. A. (2021, May 16). Durability of mRNA-1273-induced antibodies against SARS-CoV-2 variants. bioRxiv. https://doi.org/10.1101/2021.05.13.444010

Piccoli, L., Park, Y. J., Tortorici, M. A., Czudnochowski, N., Walls, A. C., Beltramello, M., SilacciFregni, C., Pinto, D., Rosen, L. E., Bowen, J. E., Acton, O. J., Jaconi, S., Guarino, B., Minola, A., Zatta, F., Sprugasci, N., Bassi, J., Peter, A., De Marco, A., Nix, J. C., Mele, F., Jovic, S., Rodriguez, B. F., Gupta, S. V., Jin, F., Piumatti, G., Lo Presti, G., Pellanda, A. F., Biggiogero, M., Tarkowski, M., Pizzuto, M. S., Cameroni, E., Havenar-Daughton, C., Smithey, M., Hong, D., Lepori, V., Albanese, E., Ceschi, A., Bernasconi, E., Elzi, L., Ferrari, P., Garzoni, C., Riva, A., Snell, G., Sallusto, F., Fink, K., Virgin, H. W., Lanzavecchia, A., Corti, D., \& Veesler, D. (2020, Nov 12). Mapping neutralizing and immunodominant sites on the SARS-CoV-2 spike receptor-binding domain by structure-guided high-resolution serology. Cell, 183(4), 1024-1042.e1021. https://doi.org/10.1016/j.cell.2020.09.037

Pinto, D., Park, Y. J., Beltramello, M., Walls, A. C., Tortorici, M. A., Bianchi, S., Jaconi, S., Culap, K., Zatta, F., De Marco, A., Peter, A., Guarino, B., Spreafico, R., Cameroni, E., Case, J. B., Chen, R. E., Havenar-Daughton, C., Snell, G., Telenti, A., Virgin, H. W., Lanzavecchia, A., Diamond, M. S., Fink, K., Veesler, D., \& Corti, D. (2020, Jul). Crossneutralization of SARS-CoV-2 by a human monoclonal SARS-CoV antibody. Nature, 583(7815), 290-295. https://doi.org/10.1038/s41586-020-2349-y

Rappazzo, C. G., Tse, L. V., Kaku, C. I., Wrapp, D., Sakharkar, M., Huang, D., Deveau, L. M., Yockachonis, T. J., Herbert, A. S., Battles, M. B., O'Brien, C. M., Brown, M. E., Geoghegan, J. C., Belk, J., Peng, L., Yang, L., Hou, Y., Scobey, T. D., Burton, D. R., Nemazee, D., Dye, J. M., Voss, J. E., Gunn, B. M., McLellan, J. S., Baric, R. S., Gralinski, L. E., \& Walker, L. M. (2021, Feb 19). Broad and potent activity against SARS-like viruses by an engineered human monoclonal antibody. Science, 371(6531), 823-829.

https://doi.org/10.1126/science.abf4830

Richardson, J. S., Getzoff, E. D., \& Richardson, D. C. (1978, Jun). The beta bulge: a common small unit of nonrepetitive protein structure. Proc Natl Acad Sci U S A, 75(6), 2574-2578. https://doi.org/10.1073/pnas.75.6.2574

Robbiani, D. F., Gaebler, C., Muecksch, F., Lorenzi, J. C. C., Wang, Z., Cho, A., Agudelo, M., Barnes, C. O., Gazumyan, A., Finkin, S., Hagglof, T., Oliveira, T. Y., Viant, C., Hurley, A., 
964

Hoffmann, H. H., Millard, K. G., Kost, R. G., Cipolla, M., Gordon, K., Bianchini, F., Chen, S. T., Ramos, V., Patel, R., Dizon, J., Shimeliovich, I., Mendoza, P., Hartweger, H., Nogueira, L., Pack, M., Horowitz, J., Schmidt, F., Weisblum, Y., Michailidis, E., Ashbrook, A. W., Waltari, E., Pak, J. E., Huey-Tubman, K. E., Koranda, N., Hoffman, P. R., West, A. P., Jr., Rice, C. M., Hatziioannou, T., Bjorkman, P. J., Bieniasz, P. D., Caskey, M., \& Nussenzweig, M. C. (2020, Aug). Convergent antibody responses to SARS-CoV-2 in convalescent individuals. Nature, 584(7821), 437-442. https://doi.org/10.1038/s41586-020-2456-9

Robert, X., \& Gouet, P. (2014, Jul). Deciphering key features in protein structures with the new ENDscript server. Nucleic Acids Res, 42(Web Server issue), W320-324. https://doi.org/10.1093/nar/gku316

Rogers, T. F., Zhao, F., Huang, D., Beutler, N., Burns, A., He, W. T., Limbo, O., Smith, C., Song, G., Woehl, J., Yang, L., Abbott, R. K., Callaghan, S., Garcia, E., Hurtado, J., Parren, M., Peng, L., Ramirez, S., Ricketts, J., Ricciardi, M. J., Rawlings, S. A., Wu, N. C., Yuan, M., Smith, D. M., Nemazee, D., Teijaro, J. R., Voss, J. E., Wilson, I. A., Andrabi, R., Briney, B., Landais, E., Sok, D., Jardine, J. G., \& Burton, D. R. (2020, Aug 21). Isolation of potent SARS-CoV-2 neutralizing antibodies and protection from disease in a small animal model. Science, 369(6506), 956-963. https://doi.org/10.1126/science.abc7520

Sakharkar, M., Rappazzo, C. G., Wieland-Alter, W. F., Hsieh, C. L., Wrapp, D., Esterman, E. S., Kaku, C. I., Wec, A. Z., Geoghegan, J. C., McLellan, J. S., Connor, R. I., Wright, P. F., \& Walker, L. M. (2021, Feb 23). Prolonged evolution of the human B cell response to SARSCoV-2 infection. Sci Immunol, 6(56), eabg6916. https://doi.org/10.1126/sciimmunol.abg6916

Sauer, M. M., Tortorici, M. A., Park, Y. J., Walls, A. C., Homad, L., Acton, O. J., Bowen, J. E., Wang, C., Xiong, X., de van der Schueren, W., Quispe, J., Hoffstrom, B. G., Bosch, B. J., McGuire, A. T., \& Veesler, D. (2021, Jun). Structural basis for broad coronavirus neutralization. Nat Struct Mol Biol, 28(6), 478-486. https://doi.org/10.1038/s41594-02100596-4

Soto, C., Bombardi, R. G., Branchizio, A., Kose, N., Matta, P., Sevy, A. M., Sinkovits, R. S., Gilchuk, P., Finn, J. A., \& Crowe, J. E., Jr. (2019, Feb). High frequency of shared clonotypes in human B cell receptor repertoires. Nature, 566(7744), 398-402. https://doi.org/10.1038/s41586-019-0934-8

Soto, C., Finn, J. A., Willis, J. R., Day, S. B., Sinkovits, R. S., Jones, T., Schmitz, S., Meiler, J., Branchizio, A., \& Crowe, J. E., Jr. (2020, Jul 16). PyIR: a scalable wrapper for processing billions of immunoglobulin and T cell receptor sequences using IgBLAST. BMC Bioinformatics, 21(1), 314. https://doi.org/10.1186/s12859-020-03649-5 
1006

1007

1008

1009

1010

1011

1012

1013

1014

1015

1016

1017

1018

1019

1020

1021

1022

1023

1024

1025

1026

1027

1028

1029

1030

1031

1032

1033

1034

1035

1036

1037

1038

1039

1040

1041

1042

1043

1044

1045

1046

1047

1048

1049

1050

Starr, T. N., Czudnochowski, N., Liu, Z., Zatta, F., Park, Y. J., Addetia, A., Pinto, D., Beltramello, M., Hernandez, P., Greaney, A. J., Marzi, R., Glass, W. G., Zhang, I., Dingens, A. S., Bowen, J. E., Tortorici, M. A., Walls, A. C., Wojcechowskyj, J. A., De Marco, A., Rosen, L. E., Zhou, J., Montiel-Ruiz, M., Kaiser, H., Dillen, J. R., Tucker, H., Bassi, J., Silacci-Fregni, C., Housley, M. P., di lulio, J., Lombardo, G., Agostini, M., Sprugasci, N., Culap, K., Jaconi, S., Meury, M., Dellota, E., Jr., Abdelnabi, R., Foo, S. C., Cameroni, E., Stumpf, S., Croll, T. I., Nix, J. C., Havenar-Daughton, C., Piccoli, L., Benigni, F., Neyts, J., Telenti, A., Lempp, F. A., Pizzuto, M. S., Chodera, J. D., Hebner, C. M., Virgin, H. W., Whelan, S. P. J., Veesler, D., Corti, D., Bloom, J. D., \& Snell, G. (2021, Sep). SARS-CoV-2 RBD antibodies that maximize breadth and resistance to escape. Nature, 597(7874), 97-102. https://doi.org/10.1038/s41586-021-03807-6

Starr, T. N., Greaney, A. J., Addetia, A., Hannon, W. W., Choudhary, M. C., Dingens, A. S., Li, J. Z., \& Bloom, J. D. (2021, Feb 19). Prospective mapping of viral mutations that escape antibodies used to treat COVID-19. Science, 371(6531), 850-854. https://doi.org/10.1126/science.abf9302

Tong, P., Gautam, A., Windsor, I. W., Travers, M., Chen, Y., Garcia, N., Whiteman, N. B., McKay, L. G. A., Storm, N., Malsick, L. E., Honko, A. N., Lelis, F. J. N., Habibi, S., Jenni, S., Cai, Y., Rennick, L. J., Duprex, W. P., McCarthy, K. R., Lavine, C. L., Zuo, T., Lin, J., Zuiani, A., Feldman, J., MacDonald, E. A., Hauser, B. M., Griffths, A., Seaman, M. S., Schmidt, A. G., Chen, B., Neuberg, D., Bajic, G., Harrison, S. C., \& Wesemann, D. R. (2021, Sep 16). Memory B cell repertoire for recognition of evolving SARS-CoV-2 spike. Cell, 184(19), 4969-4980.e4915. https://doi.org/10.1016/j.cell.2021.07.025

Tortorici, M. A., Beltramello, M., Lempp, F. A., Pinto, D., Dang, H. V., Rosen, L. E., McCallum, M., Bowen, J., Minola, A., Jaconi, S., Zatta, F., De Marco, A., Guarino, B., Bianchi, S., Lauron, E. J., Tucker, H., Zhou, J., Peter, A., Havenar-Daughton, C., Wojcechowskyj, J. A., Case, J. B., Chen, R. E., Kaiser, H., Montiel-Ruiz, M., Meury, M., Czudnochowski, N., Spreafico, R., Dillen, J., Ng, C., Sprugasci, N., Culap, K., Benigni, F., Abdelnabi, R., Foo, S. C., Schmid, M. A., Cameroni, E., Riva, A., Gabrieli, A., Galli, M., Pizzuto, M. S., Neyts, J., Diamond, M. S., Virgin, H. W., Snell, G., Corti, D., Fink, K., \& Veesler, D. (2020, Nov 20). Ultrapotent human antibodies protect against SARS-CoV-2 challenge via multiple mechanisms. Science, 370(6519), 950-957. https://doi.org/10.1126/science.abe3354

Tortorici, M. A., Czudnochowski, N., Starr, T. N., Marzi, R., Walls, A. C., Zatta, F., Bowen, J. E., Jaconi, S., Di lulio, J., Wang, Z., De Marco, A., Zepeda, S. K., Pinto, D., Liu, Z., Beltramello, M., Bartha, I., Housley, M. P., Lempp, F. A., Rosen, L. E., Dellota, E., Jr., Kaiser, H., Montiel-Ruiz, M., Zhou, J., Addetia, A., Guarino, B., Culap, K., Sprugasci, N., Saliba, C., Vetti, E., Giacchetto-Sasselli, I., Fregni, C. S., Abdelnabi, R., Foo, S. C., HavenarDaughton, C., Schmid, M. A., Benigni, F., Cameroni, E., Neyts, J., Telenti, A., Virgin, H. W., Whelan, S. P. J., Snell, G., Bloom, J. D., Corti, D., Veesler, D., \& Pizzuto, M. S. (2021, Sep). Broad sarbecovirus neutralization by a human monoclonal antibody. Nature, 597(7874), 103-108. https://doi.org/10.1038/s41586-021-03817-4 
1051

1052

1053

1054

1055

1056

1057

1058

1059

1060

1061

1062

1063

1064

1065

1066

1067

1068

1069

1070

1071

1072

1073

1074

1075

1076

1077

1078

1079

1080

1081

1082

1083

1084

1085

1086

1087

1088

1089

1090

1091

1092

1093

1094

Wang, P., Casner, R. G., Nair, M. S., Yu, J., Guo, Y., Wang, M., Chan, J. F., Cerutti, G., Iketani, S., Liu, L., Sheng, Z., Chen, Z., Yuen, K. Y., Kwong, P. D., Huang, Y., Shapiro, L., \& Ho, D. D. (2021, Nov 26). A monoclonal antibody that neutralizes SARS-CoV-2 variants, SARSCoV, and other sarbecoviruses. Emerg Microbes Infect, 1-34. https://doi.org/10.1080/22221751.2021.2011623

Wang, P., Nair, M. S., Liu, L., Iketani, S., Luo, Y., Guo, Y., Wang, M., Yu, J., Zhang, B., Kwong, P. D., Graham, B. S., Mascola, J. R., Chang, J. Y., Yin, M. T., Sobieszczyk, M., Kyratsous, C. A., Shapiro, L., Sheng, Z., Huang, Y., \& Ho, D. D. (2021, May). Antibody resistance of SARS-CoV-2 variants B.1.351 and B.1.1.7. Nature, 593(7857), 130-135. https://doi.org/10.1038/s41586-021-03398-2

Wang, Z., Lorenzi, J. C. C., Muecksch, F., Finkin, S., Viant, C., Gaebler, C., Cipolla, M., Hoffmann, H. H., Oliveira, T. Y., Oren, D. A., Ramos, V., Nogueira, L., Michailidis, E., Robbiani, D. F., Gazumyan, A., Rice, C. M., Hatziioannou, T., Bieniasz, P. D., Caskey, M., \& Nussenzweig, M. C. (2021, Jan 20). Enhanced SARS-CoV-2 neutralization by dimeric IgA. Science Translational Medicine, 13(577), eabf1555. https://doi.org/10.1126/scitranslmed.abf1555

Wang, Z., Muecksch, F., Schaefer-Babajew, D., Finkin, S., Viant, C., Gaebler, C., Hoffmann, H. H., Barnes, C. O., Cipolla, M., Ramos, V., Oliveira, T. Y., Cho, A., Schmidt, F., Da Silva, J., Bednarski, E., Aguado, L., Yee, J., Daga, M., Turroja, M., Millard, K. G., Jankovic, M., Gazumyan, A., Zhao, Z., Rice, C. M., Bieniasz, P. D., Caskey, M., Hatziioannou, T., \& Nussenzweig, M. C. (2021, Jul). Naturally enhanced neutralizing breadth against SARSCoV-2 one year after infection. Nature, 595(7867), 426-431. https://doi.org/10.1038/s41586021-03696-9

Wang, Z., Schmidt, F., Weisblum, Y., Muecksch, F., Barnes, C. O., Finkin, S., SchaeferBabajew, D., Cipolla, M., Gaebler, C., Lieberman, J. A., Oliveira, T. Y., Yang, Z., Abernathy, M. E., Huey-Tubman, K. E., Hurley, A., Turroja, M., West, K. A., Gordon, K., Millard, K. G., Ramos, V., Da Silva, J., Xu, J., Colbert, R. A., Patel, R., Dizon, J., Unson-O'Brien, C., Shimeliovich, I., Gazumyan, A., Caskey, M., Bjorkman, P. J., Casellas, R., Hatziioannou, T., Bieniasz, P. D., \& Nussenzweig, M. C. (2021, Apr). mRNA vaccine-elicited antibodies to SARS-CoV-2 and circulating variants. Nature, 592(7855), 616-622. https://doi.org/10.1038/s41586-021-03324-6

Wec, A. Z., Wrapp, D., Herbert, A. S., Maurer, D. P., Haslwanter, D., Sakharkar, M., Jangra, R. K., Dieterle, M. E., Lilov, A., Huang, D., Tse, L. V., Johnson, N. V., Hsieh, C. L., Wang, N., Nett, J. H., Champney, E., Burnina, I., Brown, M., Lin, S., Sinclair, M., Johnson, C., Pudi, S., Bortz, R., 3rd, Wirchnianski, A. S., Laudermilch, E., Florez, C., Fels, J. M., O'Brien, C. M., Graham, B. S., Nemazee, D., Burton, D. R., Baric, R. S., Voss, J. E., Chandran, K., Dye, J. M., McLellan, J. S., \& Walker, L. M. (2020, Aug 7). Broad neutralization of SARS-related viruses by human monoclonal antibodies. Science, 369(6504), 731-736.

https://doi.org/10.1126/science.abc7424 
1096

1097

1098

1099

1100

1101

1102

1103

1104

1105

1106

1107

1108

1109

1110

1111

1112

1113

1114

1115

1116

1117

1118

1119

1120

1121

1122

1123

1124

1125

1126

1127

1128

1129

1130

1131

1132

1133

1134

1135

Weisblum, Y., Schmidt, F., Zhang, F., DaSilva, J., Poston, D., Lorenzi, J. C., Muecksch, F., Rutkowska, M., Hoffmann, H. H., Michailidis, E., Gaebler, C., Agudelo, M., Cho, A., Wang, Z., Gazumyan, A., Cipolla, M., Luchsinger, L., Hillyer, C. D., Caskey, M., Robbiani, D. F., Rice, C. M., Nussenzweig, M. C., Hatziioannou, T., \& Bieniasz, P. D. (2020, Oct 28). Escape from neutralizing antibodies by SARS-CoV-2 spike protein variants. eLife, 9, e61312. https://doi.org/10.7554/eLife.61312

Williams, C. J., Headd, J. J., Moriarty, N. W., Prisant, M. G., Videau, L. L., Deis, L. N., Verma, V., Keedy, D. A., Hintze, B. J., Chen, V. B., Jain, S., Lewis, S. M., Arendall, W. B., 3rd, Snoeyink, J., Adams, P. D., Lovell, S. C., Richardson, J. S., \& Richardson, D. C. (2018, Jan). MolProbity: More and better reference data for improved all-atom structure validation. Protein Science, 27(1), 293-315. https://doi.org/10.1002/pro.3330

Wu, K., Werner, A. P., Moliva, J. I., Koch, M., Choi, A., Stewart-Jones, G. B. E., Bennett, H., Boyoglu-Barnum, S., Shi, W., Graham, B. S., Carfi, A., Corbett, K. S., Seder, R. A., \& Edwards, D. K. (2021, Jan 25). mRNA-1273 vaccine induces neutralizing antibodies against spike mutants from global SARS-CoV-2 variants. bioRxiv, 2021.2001.2025.427948. https://doi.org/10.1101/2021.01.25.427948

Wu, N. C., Yamayoshi, S., Ito, M., Uraki, R., Kawaoka, Y., \& Wilson, I. A. (2018, Oct 10). Recurring and adaptable binding motifs in broadly neutralizing antibodies to influenza virus are encoded on the D3-9 segment of the lg gene. Cell Host \& Microbe, 24(4), 569578.e564. https://doi.org/10.1016/j.chom.2018.09.010

Ye, J., Ma, N., Madden, T. L., \& Ostell, J. M. (2013, Jul). IgBLAST: an immunoglobulin variable domain sequence analysis tool. Nucleic Acids Res, 41(Web Server issue), W34-40. https://doi.org/10.1093/nar/gkt382

Yuan, M., Huang, D., Lee, C. D., Wu, N. C., Jackson, A. M., Zhu, X., Liu, H., Peng, L., van Gils, M. J., Sanders, R. W., Burton, D. R., Reincke, S. M., Pruss, H., Kreye, J., Nemazee, D., Ward, A. B., \& Wilson, I. A. (2021, Aug 13). Structural and functional ramifications of antigenic drift in recent SARS-CoV-2 variants. Science, 373(6556), 818-823. https://doi.org/10.1126/science.abh1139

Yuan, M., Liu, H., Wu, N. C., \& Wilson, I. A. (2021, Jan 29). Recognition of the SARS-CoV-2 receptor binding domain by neutralizing antibodies. Biochemical and Biophysical Research Communications, 538, 192-203. https://doi.org/10.1016/..bbrc.2020.10.012

Yuan, M., Wu, N. C., Zhu, X., Lee, C. D., So, R. T. Y., Lv, H., Mok, C. K. P., \& Wilson, I. A. (2020, May 8). A highly conserved cryptic epitope in the receptor binding domains of SARS- 
CoV-2 and SARS-CoV. Science, 368(6491), 630-633.

Zhou, D., Duyvesteyn, H. M. E., Chen, C. P., Huang, C. G., Chen, T. H., Shih, S. R., Lin, Y. C., Cheng, C. Y., Cheng, S. H., Huang, Y. C., Lin, T. Y., Ma, C., Huo, J., Carrique, L., Malinauskas, T., Ruza, R. R., Shah, P. N. M., Tan, T. K., Rijal, P., Donat, R. F., Godwin, K., Buttigieg, K. R., Tree, J. A., Radecke, J., Paterson, N. G., Supasa, P., Mongkolsapaya, J., Screaton, G. R., Carroll, M. W., Gilbert-Jaramillo, J., Knight, M. L., James, W., Owens, R. J., Naismith, J. H., Townsend, A. R., Fry, E. E., Zhao, Y., Ren, J., Stuart, D. I., \& Huang, K. A. (2020, Oct). Structural basis for the neutralization of SARS-CoV-2 by an antibody from a convalescent patient. Nat Struct Mol Biol, 27(10), 950-958. https://doi.org/10.1038/s41594-

Zhou, P., Yuan, M., Song, G., Beutler, N., Shaabani, N., Huang, D., He, W. T., Zhu, X., 020-0480-y

Zost, S. J., Gilchuk, P., Chen, R. E., Case, J. B., Reidy, J. X., Trivette, A., Nargi, R. S., Sutton, R. E., Suryadevara, N., Chen, E. C., Binshtein, E., Shrihari, S., Ostrowski, M., Chu, H. Y., Didier, J. E., MacRenaris, K. W., Jones, T., Day, S., Myers, L., Eun-Hyung Lee, F., Nguyen, D. C., Sanz, I., Martinez, D. R., Rothlauf, P. W., Bloyet, L. M., Whelan, S. P. J., Baric, R. S., Thackray, L. B., Diamond, M. S., Carnahan, R. H., \& Crowe, J. E., Jr. (2020, Sep). Rapid Callaghan, S., Yong, P., Anzanello, F., Peng, L., Ricketts, J., Parren, M., Garcia, E., Rawlings, S. A., Smith, D. M., Nemazee, D., Teijaro, J. R., Rogers, T. F., Wilson, I. A., Burton, D. R., \& Andrabi, R. (2021, Mar 31). A protective broadly cross-reactive human antibody defines a conserved site of vulnerability on beta-coronavirus spikes. bioRxiv. https://doi.org/10.1101/2021.03.30.437769

1164 isolation and profiling of a diverse panel of human monoclonal antibodies targeting the SARS-CoV-2 spike protein. Nat Med, 26(9), 1422-1427. https://doi.org/10.1038/s41591020-0998-X 